Abanico Veterinario. Enero-Diciembre 2021; 11:1-26. http://dx.doi.org/10.21929/abavet2021.47

Revisión de Literatura. Recibido: 03/08/2021. Aceptado:15/12/2021. Publicado: 30/12/2021. Clave: e2021-52.

https://www.youtube.com/watch?v=cFnXFVcpFMU

\title{
Bioquímica y vías metabólicas de polisacáridos, lípidos y proteínas
}

\section{Biochemistry and metabolic pathways of polysaccharides, lipids, and proteins \\ Pacheco-Gómez Verónica*1 ID, Caballero-Zamora Alejandra² ID, Martínez-González Sergio $^{3}$ ID, Prado-Rebolledo Omar ${ }^{\text {ID }}$, García-Casillas Arturo**4 ID}

${ }^{1}$ Estudiante de Maestría en Ciencias Agropecuarias, Universidad Autónoma Metropolitana. México. 2Departamento de Producción Agrícola y Animal, Universidad Autónoma Metropolitana. México. 3 Unidad

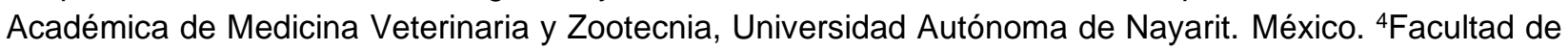
Medicina Veterinaria y Zootecnia, Universidad de Colima. México. *Autor responsable: Pacheco-Gómez Verónica. Calzada del Hueso 1100, Col. Villa Quietud, Delegación Coyoacán, CP. 04960 Ciudad de México. México. ${ }^{*}$ Autor de correspondencia: García-Casillas Arturo. Facultad de Medicina Veterinaria y Zootecnia, Universidad de Colima. Kilómetro 40 Carretera Colima-Manzanillo, S/N, Tecomán, Colima. México. CP 28100. E-mail: veropach86@yahoo.com.mx, acaballeroz@correo.xoc.uam.mx, sergio.martinez@uan.edu.mx,omarpr@ucol.mx,cesargarciacasillas@hotmail.com

\section{RESUMEN}

Las células eucariotas son estructuras complejas, capaces de replicarse y realizar una amplia gama de tareas en organismos multicelulares. Sin embargo, también obedecen las leyes de la química y la física que determinan el metabolismo de los sistemas vivos. En consecuencia, la biología celular busca comprender los procesos metabólicos en términos de reacciones de anabolismo y catabolismo molecular. Esta revisión considera la composición química y las propiedades de los polisacáridos, lípidos y proteínas como responsables en última instancia de todas las actividades celulares. Los átomos y enlaces bioquímicos de estas macromoléculas determinan toda la dinámica celular, por lo que en la primera parte de cada capítulo se repasa la naturaleza de los grupos funcionales hidroxilo, amino y carboxilo, responsables de la formación de monosacáridos, aminoácidos y ácidos grasos. El resto de cada capítulo analiza la génesis y lisis de estas moléculas dentro de cada organelo celular, para la formación de acetilCoenzima A y la liberación de su energía en el ciclo de Krebs. Así, la bioquímica del metabolismo celular, puede entenderse en términos de las estructuras y funciones de tres principales moléculas orgánicas.

Palabras clave: glucogenogénesis, glucólisis, lipogénesis, lipólisis, proteogénesis, proteólisis.

\section{ABSTRACT}

The eukaryotic cells are complex structures, capable of replication and performing a wide range of tasks in multicellular organisms. However, they also obey the laws of chemistry and physics that determine the metabolism of living systems. Consequently, cell biology seeks to understand metabolic processes in terms of reactions of anabolism and molecular catabolism. This review considers the chemical composition and properties of polysaccharides, lipids, and proteins as ultimately responsible for all cellular activities. The atoms and biochemical bonds of these macromolecules determine all cell dynamics, which is why the first part of each chapter reviews the nature of the functional group's hydroxyl, amino and carboxyl, responsible for the formation of monosaccharides, amino acids and fatty acids. The rest of each chapter analyzes the genesis and lysis of these molecules within each cell organelle, for the formation of acetyl-coenzyme A and the liberation of energy in the Krebs cycle. Thus, the biochemistry of cell metabolism can be understood in terms of the structures and functions of three main organic molecules polysaccharides, lipids and proteins. Keywords: glycogenogenesis, glycolysis, lipogenesis, lipolysis, proteogenesis, proteolysis. 


$\begin{array}{ll}\text { ABREVIATURAS } \\ \text { aa } & \text { aminoácidos } \\ \text { Ac } & \text { acetona } \\ \text { AcAc } & \text { acetoacetato } \\ \text { ADN } & \text { desoxirribonucleico } \\ \text { AGNE } & \text { ácidos grasos no esterificados } \\ \text { Arg } & \text { arginina } \\ \text { ARNm } & \text { ribonucleico mensajero } \\ \text { ARNt } & \text { ribonucleico de transferencia } \\ \mathrm{C} & \text { carbono } \\ \mathrm{C}=\mathrm{O} & \text { grupo carbonilo } \\ \mathrm{C} 16: 0 & \text { palmítico } \\ \mathrm{C}_{3} \mathrm{H}_{3} \mathrm{O}_{3} & \text { piruvato } \\ \mathrm{Ca}^{2+} & \text { ion calcio } \\ \mathrm{CO}_{2} & \text { dióxido de carbono } \\ \mathrm{COCH}_{3} & \text { grupo acetilo }\end{array}$

\begin{tabular}{|c|c|}
\hline $\mathrm{COOH}$ & grupo carboxilo \\
\hline Gln & glutamina \\
\hline GLU & glucosa \\
\hline $\mathrm{H}$ & hidrógeno \\
\hline $\mathrm{H}_{2} \mathrm{O}$ & agua \\
\hline $\mathrm{HCO}_{3}^{-}$ & anión hidrógenocarbonato \\
\hline $\mathrm{N}$ & nitrógeno \\
\hline $\mathrm{NADPH}+\mathrm{H}^{+}$ & nicotinamida adenina dinucleótido fosfato \\
\hline $\mathrm{NH}_{2}$ & grupo amino \\
\hline $\mathrm{NH}_{4}^{+}$ & ion amonio \\
\hline $\mathrm{O}$ & oxígeno \\
\hline $\mathrm{OH}$ & grupo hidroxilo \\
\hline $\mathrm{PO}_{4}^{2-}$ & grupo fosfato \\
\hline TAG & triacilgliceroles \\
\hline$\beta-\mathrm{HBA}$ & $\beta$-hidroxibutirato \\
\hline
\end{tabular}

\section{INTRODUCCIÓN}

Las células eucariontes están compuestas de agua, iones inorgánicos y miles de moléculas orgánicas (Cooper, 2019b). Que participan en sistemas para extraer, transformar y utilizar energía del medio ambiente (Tortora et al., 2019b). Lo que permite a los organismos realizar trabajos mecánicos, químicos, osmóticos y eléctricos (Ameer et al., 2018; Rodwell, 2018a; Melo \& Cuamatzi, 2019). La mayoría de estas moléculas orgánicas pertenecen a una de tres clases de polímeros: i) polisacáridos, ii) lípidos y iii) proteínas (Fails \& Magee, 2018a). Estos polímeros constituyen entre el 80 y $90 \%$ del peso de la mayoría de las células (Pavlinov et al., 2019) y están formados por la unión (polimerización) de varios componentes químicos de bajo peso molecular: carbohidratos, ácidos grasos y aminoácidos, respectivamente (Guoyao, 2017c). La interacción entre estos componentes es dinámica; los cambios en un componente provocan cambios de coordinación o compensación en otro (Tortora et al., 2019b). La bioquímica es quien describe en términos moleculares, este conjunto de interacciones (Pol et al., 2014). Considerando dos vías metabólicas de manera principal: i) catabolismo para obtener acetil-Coenzima A (Tortora \& Derrickson, 2018b) y ii) anabolismo para adquirir moléculas más grandes (Pol et al., 2014; Engelking, 2015; Menzies et al., 2016). Contribuyendo así, con conocimientos y aplicaciones prácticas en la medicina (Gundu, 2020), la agricultura (Milani et al., 2017), la nutrición (Preethi \& Sekar 2021) y la industria (Wu et al., 2019). Pero su principal preocupación es la célula como organismo vivo (Cooper, 2019a).

Por lo tanto, esta revisión ofrece una descripción general de la dinámica molecular en la interfaz del metabolismo de polisacáridos, lípidos y proteínas, para fundamentar las bases de la biología celular.

\section{PROPIEDADES FISICOQUÍMICAS DE LOS POLISACÁRIDOS}

Los polisacáridos son moléculas orgánicas formadas por más de diez monosacáridos, unidos mediante enlaces O-glucosídicos (Yang et al., 2015; Guoyao, 2017c). Su fórmula general contiene átomos de carbono (C) hidratados con moléculas de agua $\left(\mathrm{H}_{2} \mathrm{O}\right)$ (Bender \& Mayes, 2018c). Por lo tanto, presentan solubilidad en este fluido y su clasificación se establece con base a la posición de su grupo carbonilo $(\mathbf{C}=\mathbf{0})($ Chavarría \& Cárabez, 2018). Formado por un átomo de $\mathrm{C}$ unido a un átomo de oxígeno (0) mediante 
un doble enlace (Cooper, 2019b). Si el grupo $\mathrm{C}=\mathrm{O}$ se localiza en el extremo de la molécula, es una aldosa. $\mathrm{Si}$ el grupo $\mathrm{C}=\mathrm{O}$ se localiza en medio de la molécula, es una cetosa (Mckee \& Mckee, 2014a; Delbianco et al., 2016).

Los polisacáridos son la principal fuente biológica de almacenamiento y consumo de energía (Chavarría \& Cárabez, 2018) y forman parte de la estructura orgánica de todos los seres vivos (Cooper, 2019c). Su ingreso en el organismo, es a partir del alimento y su hidrólisis (ruptura de enlaces O-glucosídicos) por amilasas producidas en las parótidas (Kumar \& Chakravarty, 2018), y glucógeno fosforilasas y glucosa-6-fosfatasas, producidas por las células acinares del páncreas (Boticario \& Cascales, 2012; Cárabez et al., 2018a). Posterior a esta hidrólisis se libera al monómero glucosa (GLU), con la fórmula química $\mathrm{C}_{6} \mathrm{H}_{12} \mathrm{O}_{6}$ (Bender \& Mayes, 2018b), para ser absorbida por medio del epitelio intestinal (Fails \& Magee, 2018a) y distribuida por el torrente sanguíneo a los diferentes tejidos (Dashty, 2013; Oosterveer \& Schoonjans, 2014), donde presenta cinco principales vías metabólicas: i) glucogenogénesis, ii) ruta de las pentosas fosfato iii) glucogenólisis, iv) glucólisis y v) glucogénesis (Appleton et al., 2013a; Nelson \& Cox, 2017b).

\section{ANABOLISMO DEL GLUCÓGENO (GLUCOGENOGÉNESIS)}

La glucogenogénesis se lleva a cabo en miocitos (Engelking, 2015) y hepatocitos (Tortora \& Derrickson, 2018b), donde la GLU ingresa al citoplasma, para ser fosforilada [adición de un grupo fosfato $\left(\mathrm{PO}_{4}{ }^{2-}\right)$ ], a partir de adenosina trifosfato (ATP) (Rui, 2014) (Figura 1).
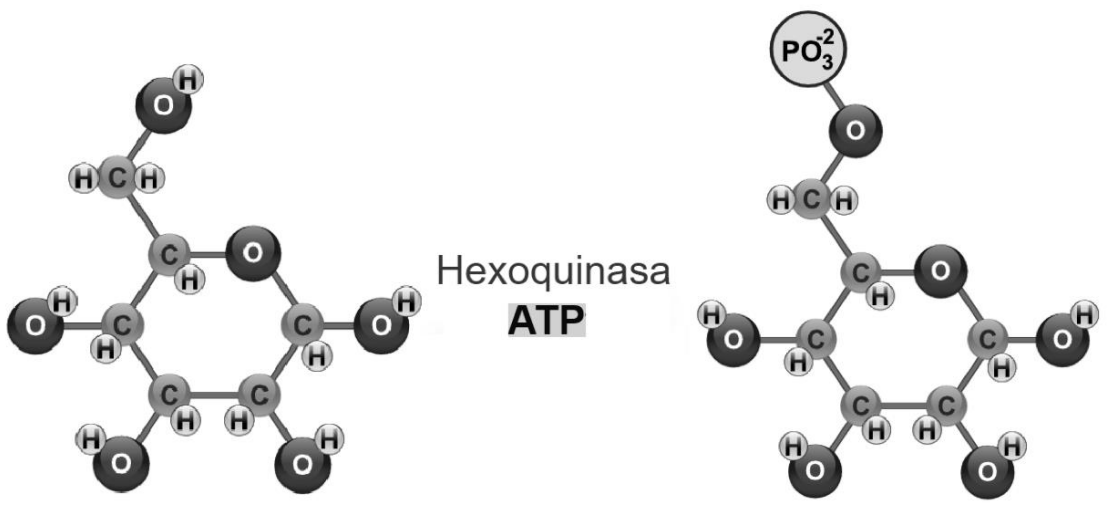

Figura 1. Síntesis de glucosa-6-fosfato

La glucosa-6-fosfato resultante, abunda en el citoplasma de todas las células (Litwack, 2018a) y cuando sus niveles son elevados, la fosfoglucomutasa transfiere el grupo $\mathrm{PO}_{4}{ }^{2-}$ del C6 al C1 sintetizando glucosa-1-fosfato (Delbianco et al., 2016). La uridina trifosfato, interacciona con glucosa-1-fosfato, formando uridina difosfato glucosa (Fox et al., 2017). La insulina, activa a la glucógeno sintasa 1 expresada en miocitos y/o la glucógeno sintasa 2 expresada en hepatocitos (Gadupudi et al., 2016), para que el grupo hidroxilo $(\mathbf{O H})$ de la uridina difosfato glucosa se fije al glucógeno (creando un enlace $O$ glucosídico), alargando al polisacárido (Figura 2). 


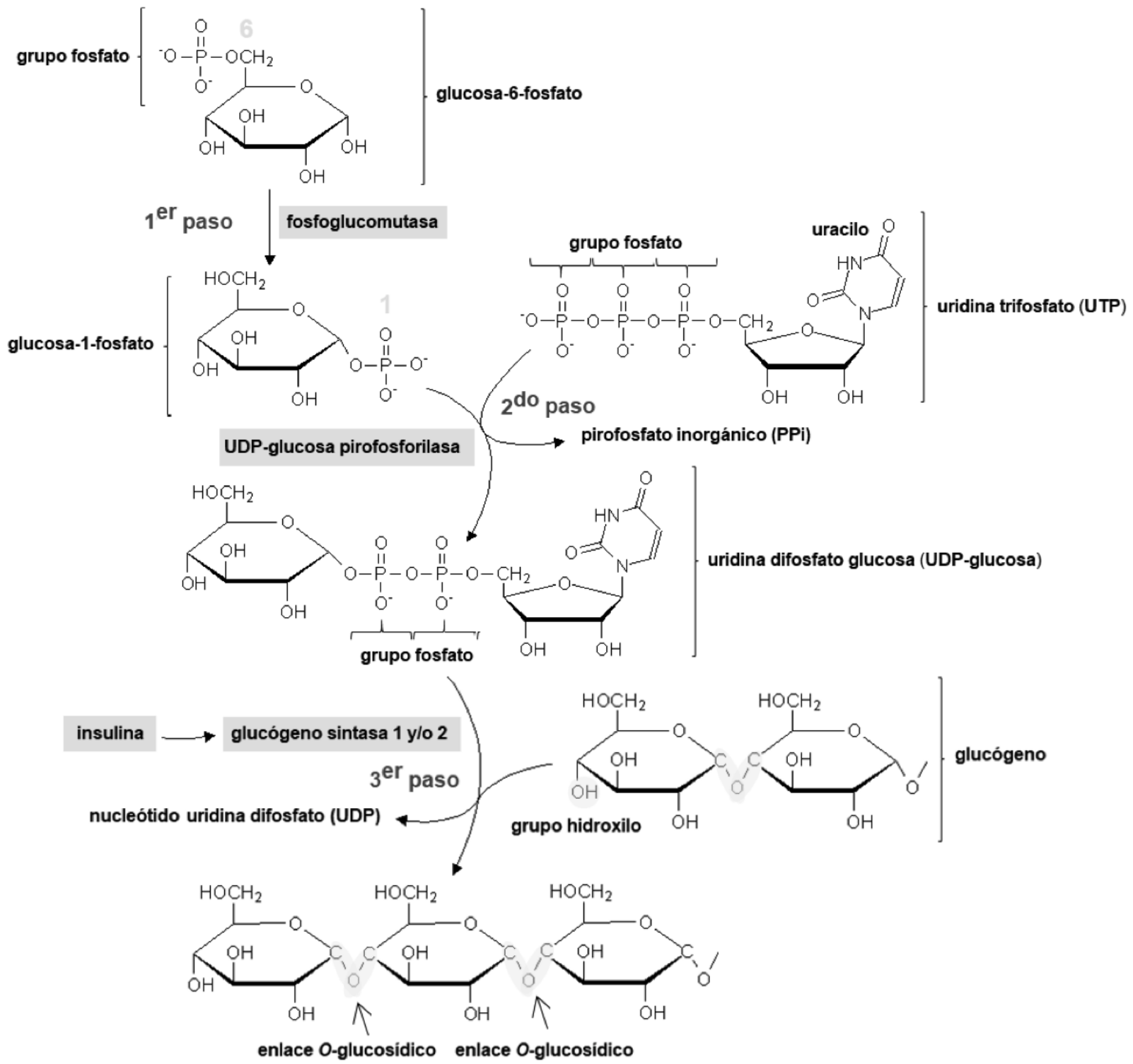

Figura 2. Glucogenogénesis. Detalle del enlace $O$-glucosídico

\section{RUTA DE LAS PENTOSAS FOSFATO}

Este proceso tiene lugar en el citoplasma y se divide en dos, la fase oxidativa y la fase no oxidativa (Tortora \& Derrickson, 2018b). La fase oxidativa, presenta de tres reacciones: i) la glucosa-6-fosfato es deshidrogenada [pierde 2 hidrógenos $(\mathbf{H})$ ] (Nelson \& Cox, 2017b). Como producto se obtiene 6-fosfogluconolactona y una molécula de nicotinamida adenina dinucleótido fosfato $\left(\mathbf{N A D P H}+\mathbf{H}^{+}\right)$, y ii) la 6 -fosfogluconolactona es hidrolizada y como producto se obtiene 6-fosfoglucanato (Lee et al., 2019) y iii) el 6fosfoglucanato es descarboxilado [eliminación del grupo carboxilo (COOH)] (Mckee \& Mckee, 2014b). Como producto se obtiene ribulosa-5-fosfato (cetopentosa), una molécula de $\mathrm{NADPH}+\mathrm{H}^{+}$y dióxido de carbono $\left(\mathbf{C O}_{2}\right)$ (Stincone et al., 2015).

Durante la fase no oxidativa la ribulosa-5-fosfato, puede presentar isomerización y ser transformada en otra molécula que posee los mismos átomos, pero dispuestos de forma 
distinta (Madigan et al., 2019a). En otra palabras, cambia de posición su grupo $\mathrm{C}=\mathrm{O}$ para convertirse en a ribosa 5-fosfato (aldopentosa) (Cárabez et al., 2018b). Por lo tanto, las principales funciones de la ruta de las pentosas fosfato son: i) sintetizar monosacáridos de cinco C y ii) generar $\mathrm{NADPH}+\mathrm{H}^{+}$(Nelson \& Cox, 2017b).

\section{CATABOLISMO DEL GLUCÓGENO (GLUCOGENÓLISIS)}

Este proceso tiene lugar en el citoplasma de casi todas las células, aunque de manera especial en los miocitos del músculo y en los hepatocitos del hígado (Mckee \& Mckee, 2014c). Cuando los niveles de GLU en la sangre son bajos, la adrenalina o epinefrina en el músculo y el glucagón en el hígado, activan las proteínas quinasas (Ahern, 2019d), y éstas realizan la fosforilación a glucógeno fosforilasa, por lo que esta enzima se activa (Mckee \& Mckee, 2014c). La glucógeno fosforilasa cataliza la transferencia de un ortofosfato inorgánico en el C1 del glucógeno (Fox et al., 2017), y este cambio rompe el enlace O-glucosídico y libera glucosa-1-fosfato (Figura 3). La glucosa-1-fosfato es transformada en glucosa-6-fosfato, transfiriendo el grupo $\mathrm{PO}_{4}{ }^{2-}$ del $\mathrm{C} 1$ al $\mathrm{C} 6$ (Ahern, 2019d).

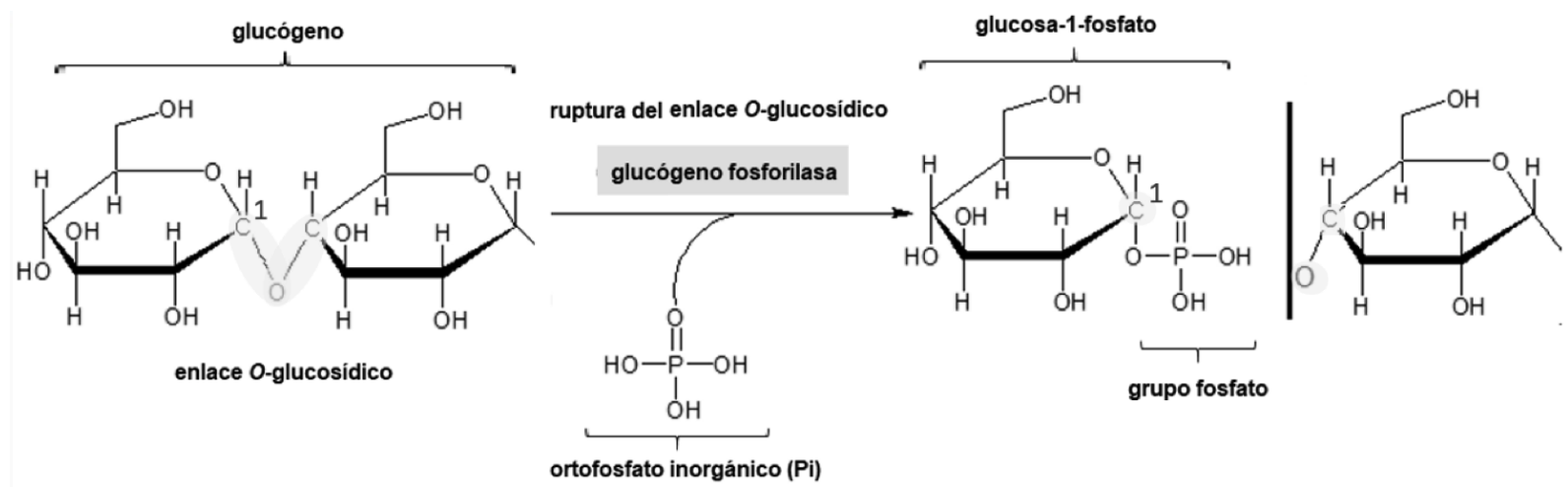

Figura 3. Glucogenólisis y síntesis de glucosa-1-fosfato

\section{CATABOLISMO DE LA GLUCOSA (GLUCÓLISIS)}

Este proceso consiste en la degradación de la glucosa-6-fosfato para obtener acetilCoenzima A, a partir del piruvato $\left(\mathrm{C}_{3} \mathrm{H}_{3} \mathrm{O}_{3}\right)$ (Ferrier, 2017b). Se lleva a cabo en el citoplasma donde la glucosa-6-fosfato (aldohexosa), presenta isomerización (Mckee \& Mckee, 2014c) y es transformada en fructosa-6-fosfato (cetohexosa) al cambiar de lugar su grupo $\mathrm{C}=\mathrm{O}$ (Figura 4). 


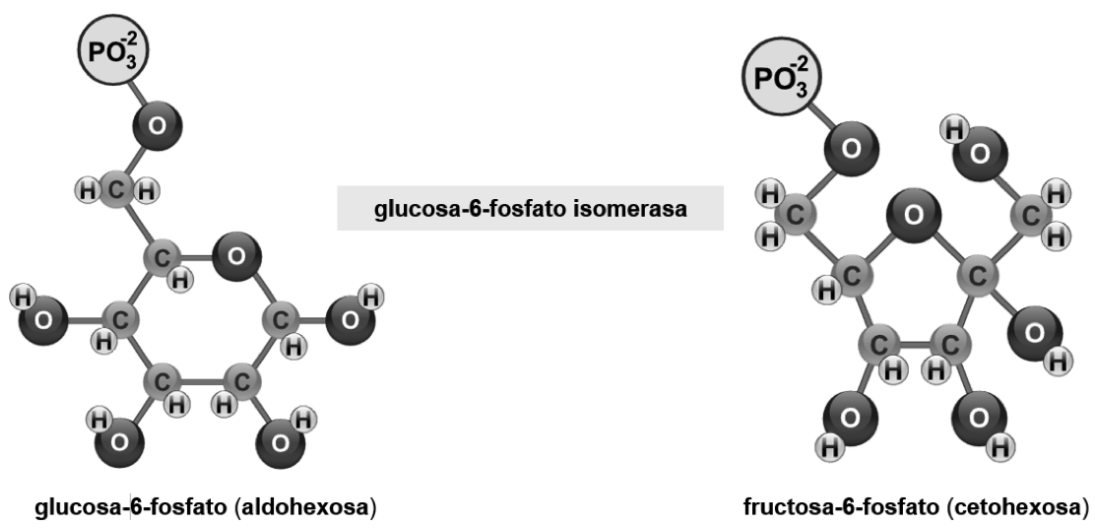

Figura 4. Isomerización de glucosa-6-fosfato a fructosa-6-fosfato

La fructosa-6-fosfato, es fosforilada (Figura 5), a partir de ATP en los C1 y C6 (Tortora et al., 2019a), para dar lugar a la fructosa-1,6-bifosfato (Delbianco et al., 2016; Ferrier, 2017a).

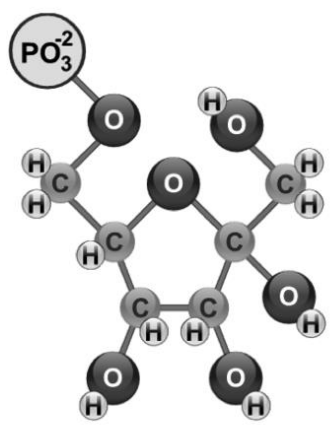

fructosa-6-fosfato

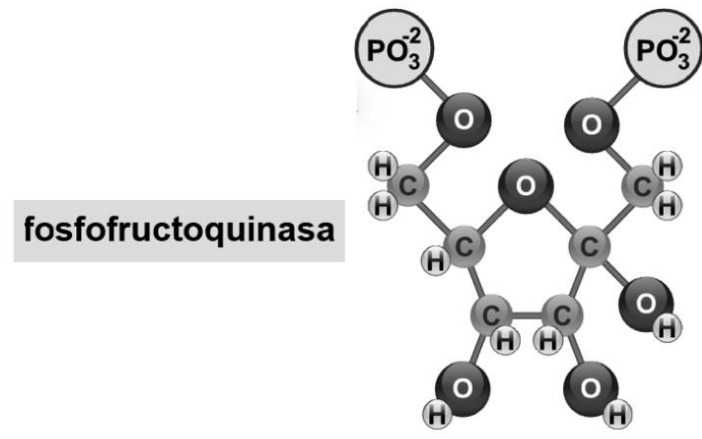

fructosa-1,6-bifosfato

Figura 5. Síntesis de fructosa-1,6-bifosfato

Posteriormente la fructosa-1,6-bifosfato (Figura 6) es dividida en dos: i) gliceraldehido3-fosfato y ii) dihidroxiacetona fosfato (Melo \& Cuamatzi, 2019).

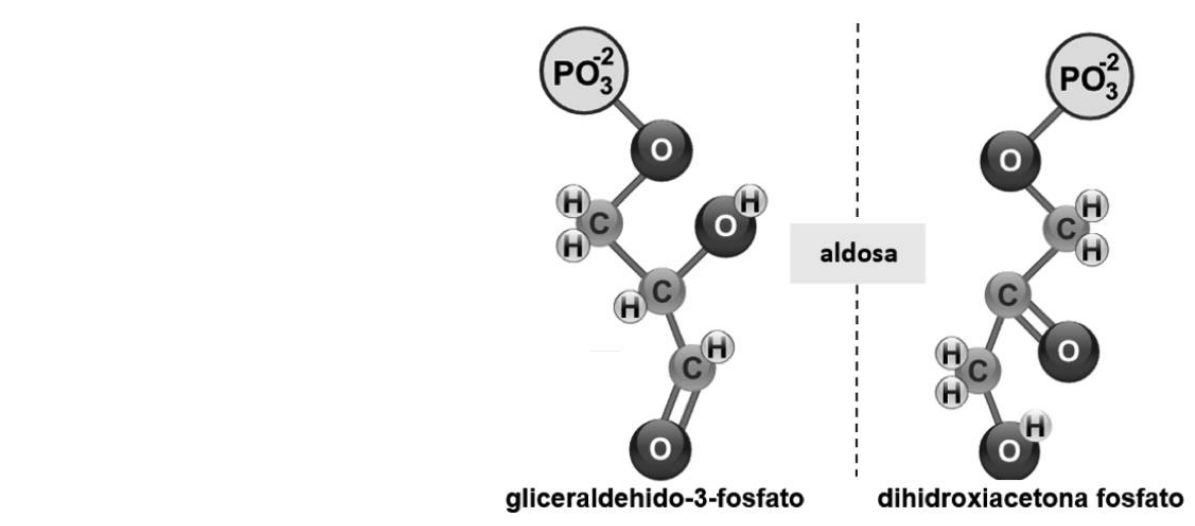

Figura 6. División de fructosa-1,6-bifosfato 
El gliceraldehido-3-fosfato es oxidado y fosforilado, en los C1 y C3 formando 1,3bifosfoglicerato (Mckee \& Mckee, 2014c) (Figura 7). Posteriormente, transfiere su grupo $\mathrm{PO}_{4}{ }^{2-}$, para sintetizar ATP (Ahern, 2019b) y se transforma en 3-fosfoglicerato (Voet et al., 2016; Tortora \& Derrickson, 2018b).

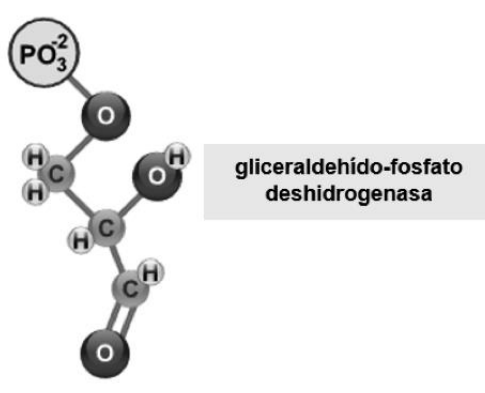

gliceraldehido-3-fosfato
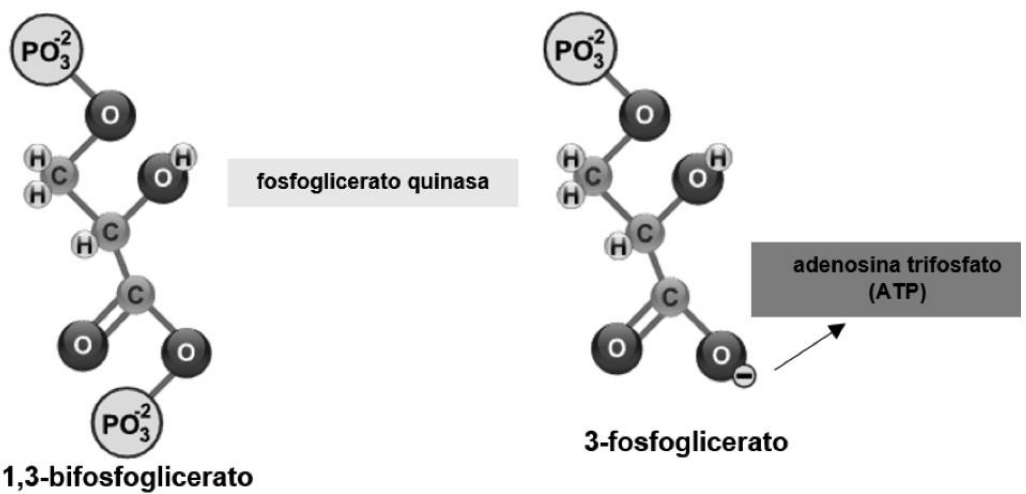

Figura 7. De gliceraldehido-3-fosfato a 3-fosfoglicerato

El 3-fosfoglicerato presenta isomerización y su grupo $\mathrm{PO}_{4}{ }^{2-}$ cambia del $\mathrm{C} 3$ al C2, transformado la molécula en 2-fosfoglicerato (Nelson \& Cox, 2017b). A continuación la enolasa propicia la formación de un enlace doble (Voet et al., 2016), eliminando una molécula de $\mathrm{H}_{2} \mathrm{O}$ y formando fosfoenolpiruvato (Guoyao, 2017f; Bender \& Mayes, 2018a) (Figura 8).

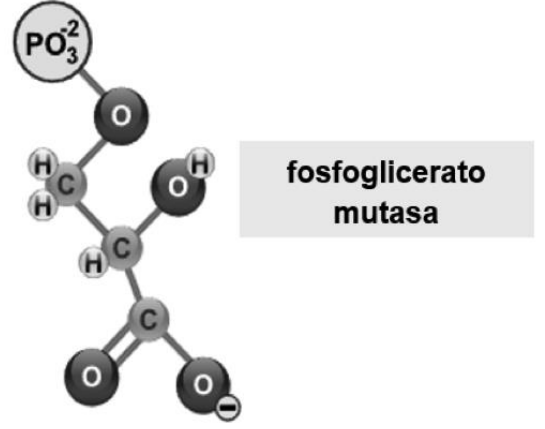

3-fosfoglicerato

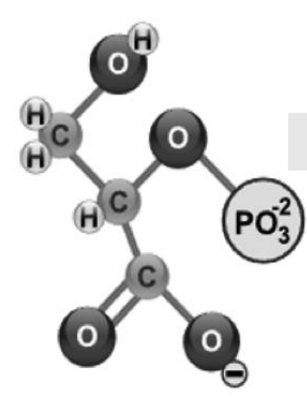

2-fosfoglicerato enolasa

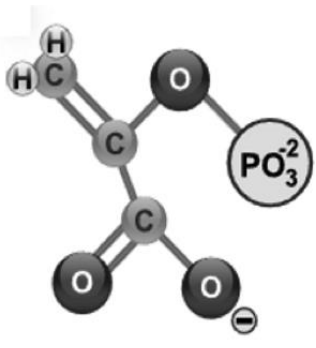

fosfoenolpiruvato

Figura 8. De 3-fosfoglicerato a fosfoenolpiruvato

El fosfoenolpiruvato transfiere su grupo $\mathrm{PO}_{4}{ }^{2-}$ (Cárabez et al., 2018a), para sintetizar ATP (Ahern, 2019b) y se transforma en $\mathrm{C}_{3} \mathrm{H}_{3} \mathrm{O}_{3}$ (Botham \& Mayes, 2018d), molécula que es atraída hacia la matriz mitocondrial, utilizando la fuerza protón-motriz generada por la cadena respiratoria (Fails \& Magee, 2018b; Madigan et al., 2019c) (Figura 9). 


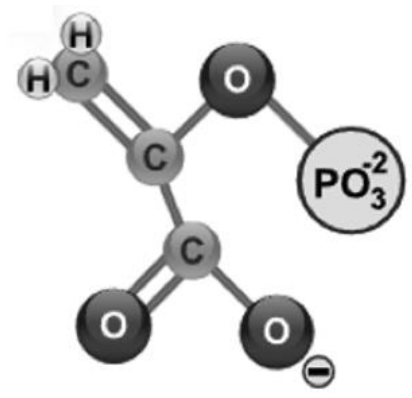

fosfoenolpiruvato piruvato quinasa

Figura 9. De fosfoenolpiruvato a piruvato

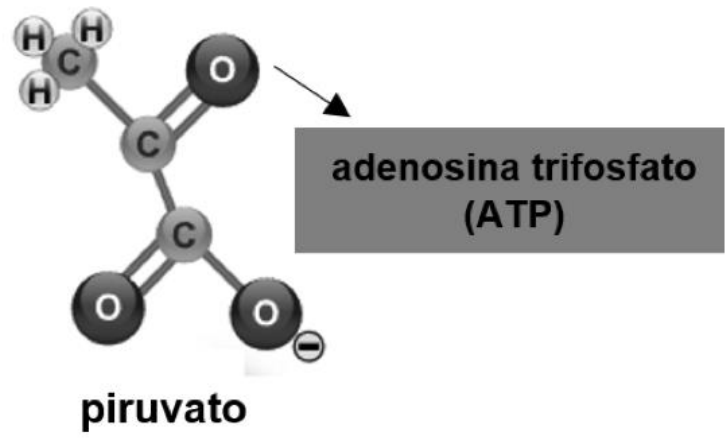

El destino del $\mathrm{C}_{3} \mathrm{H}_{3} \mathrm{O}_{3}$ que se produjo en la glucólisis, depende de la disponibilidad de $\mathrm{O}$. En condiciones anaeróbicas el $\mathrm{C}_{3} \mathrm{H}_{3} \mathrm{O}_{3}$ presenta reducción adicionando átomos de $\mathrm{H}$ para formar láctico (Tortora \& Derrickson, 2018b). En condiciones aeróbicas el $\mathrm{C}_{3} \mathrm{H}_{3} \mathrm{O}_{3}$ presenta descarboxilación y su grupo $\mathrm{COOH}$ se libera como $\mathrm{CO}_{2}$ (Stincone et al., 2015), el resto de la molécula presenta oxidación, para formar el grupo acetilo $\left(\mathbf{C O C H}_{3}\right)$. Por último la Coenzima $A$, se transfiere al grupo $\mathrm{COCH}_{3}$ formando acetil-Coenzima $A$ (Guoyao, 2017f) (Figura 10).

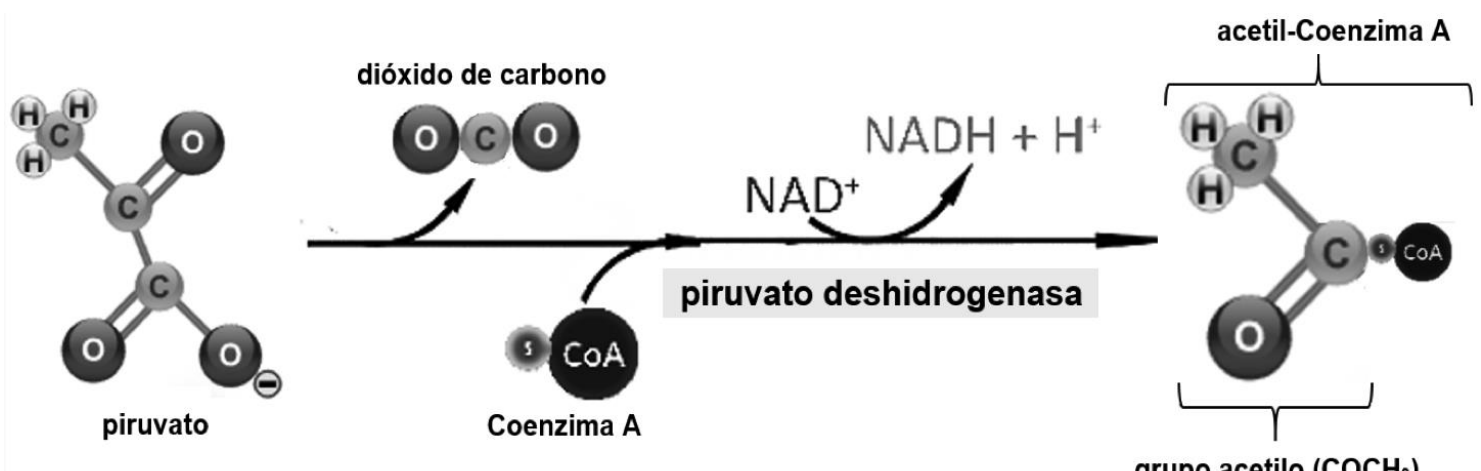

Figura 10. Descarboxilación oxidativa de piruvato

\section{PROPIEDADES FISICOQUÍMICAS DE LOS LÍPIDOS}

Los lípidos constituyen un depósito de almacenamiento energético en los adipocitos (Guoyao, 2017a). Participan en la formación de membranas fosfolipídicas de las células eucariontes y sus organelos (Schoeler \& Caesar, 2019). En el torrente sanguíneo, transportan vitaminas liposolubles p. ej., la A para la formación de tejidos blandos y mucosas (Botham \& Mayes, 2018c), la D para la absorción del ion calcio $\left(\mathbf{C a}^{2+}\right)$ (Jameson, 2017), la E como antioxidante y formación de eritrocitos (Madigan et al., 2019c) y la K que contribuye en la coagulación (Guoyao, 2017a). Además actúan como aislante térmico en los tejidos subcutáneos para retener el calor corporal (Mas, 2018b).

Su ingreso en el organismo, es a partir del alimento y su hidrólisis (ruptura de enlaces éster) por lipasas y esterasas producidas por las células acinares del páncreas (Ahern, 2019c). Posterior a esta hidrólisis se liberan ácidos grasos no esterificados (AGNE) y triacilgliceroles (TAG) (Tortora et al., 2019a), para ser absorbidos por medio del epitelio 
intestinal (Pol et al., 2014; Guoyao, 2017d), y transportados hacia los hepatocitos del hígado (Botham \& Mayes, 2018c). Donde son empaquetados en lipoproteínas de muy baja densidad (Wadhera et al., 2016), para su posterior exportación hacia los tejidos periféricos (Wang et al., 2016). Los AGNE obtenidos durante dicho proceso, son necesarios para sintetizar acetil-Coenzima A (Appleton et al., 2013d).

\section{ANABOLISMO DEL TRIACILGLICEROL (LIPOGÉNESIS)}

La lipogénesis inicia en la mitocondria, con la producción de acetil-Coenzima A (Cooper, 2019a). Debido a que la membrana de la mitocondria es impermeable al paso de acetilCoenzima A (Friedman \& Nunnari, 2014), se requiere del sistema tricarboxilato (Figura 11) y de la citrato sintasa para convertirla en citrato (Nunes-Nesi et al., 2013), por medio de la fijación de $C$ (Ameer et al., 2018), de este modo se asegura su ingreso al citoplasma celular (Botham \& Mayes, 2018c). A continuación, el citrato es trasformado nuevamente en acetil-Coenzima A por la ATP-citrato liasa (Nunes-Nesi et al., 2013; Botham \& Mayes, 2018c), obteniendo oxaloacetato y adenosina difosfato (Mas, 2018a; Tortora \& Derrickson, 2018a).

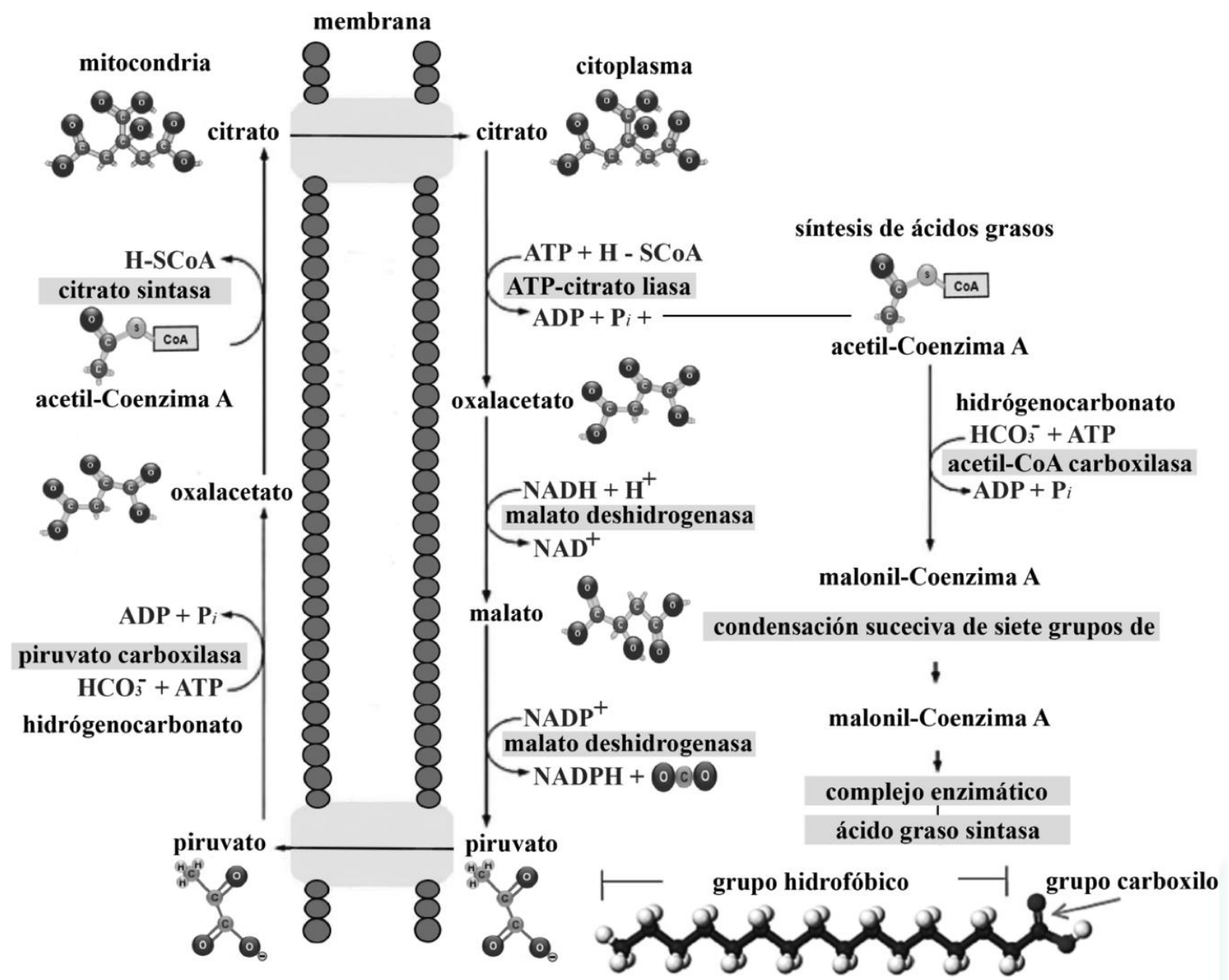

Figura 11. Sistema tricarboxilato y anabolismo de lípidos

Fuente: (García et al., 2020). 
La lipogénesis es un proceso endergónico, por lo tanto, la acetil-Coenzima A debe ser activada mediante carboxilación a través de su unión con el anión hidrógenocarbonato $\left(\mathrm{HCO}_{3}{ }^{-}\right)$en una reacción que consume ATP (Botham \& Mayes, 2018a), catalizada por la acetil-CoA carboxilasa (Cooper, 2019b). Como resultado, la acetil-Coenzima A se convierte en malonil-Coenzima A (Nelson \& Cox, 2017c). Por su parte, el oxaloacetato es reducido por malato deshidrogenasa a malato, y éste a su vez convertido en $\mathrm{C}_{3} \mathrm{H}_{3} \mathrm{O}_{3}$ por medio de la enzima málica, produciendo $\mathrm{NADPH}+\mathrm{H}^{+}$(Appleton et al., 2013e; Dashty, 2013). Posteriormente el ácido graso requiere elongación, mediante el complejo proteico ácido graso sintasa (Pol et al., 2014). Este complejo realiza condensación, reducción, deshidratación y nuevamente reducción, acoplando grupos de malonil-Coenzima A con acetil-Coenzima A (Nelson \& Cox, 2017c). Las dos reducciones mencionadas, requieren de $\mathrm{NADPH}+\mathrm{H}^{+}$(Dashty, 2013), y durante la elongación se van añadiendo grupos de dos $\mathrm{C}$ al ácido graso, sintetizando siempre al hexadecanoico o palmítico (C16:0), como producto final (Guoyao, 2017d). Posteriormente, el C16:0 es liberado del complejo proteico y puede ser elongado introduciendo $\mathrm{C}$ en su cadena, para producir otras moléculas de ácidos grasos más grandes (Botham \& Mayes, 2018c), y/o insaturado introduciendo enlaces dobles en su cadena (Cooper, 2019a). La síntesis de TAG, se lleva a cabo en el retículo endoplasmático liso (Quintero, 2014).

Una vez que se obtienen diferentes AGNE, el enlace éster de los lípidos, se establece mediante la unión de los tres grupos OH del glicerol (Nelson \& Cox, 2017c) (Figura 12), y el grupo $\mathrm{COOH}$ (la parte polar) de tres ácidos grasos (Botham \& Mayes, 2018c). Este enlace es una condensación o deshidratación donde se pierden 3 moléculas de $\mathrm{H}_{2} \mathrm{O}$ (Smith, 2020b). Debido a esta unión, los grupos polares unidos al carbohidrato no son accesibles (Pratt et al., 2016). En consecuencia, se forman moléculas no polares 0 hidrofóbicas, altamente insolubles en agua (Dowhan \& Bogdanov, 2016).

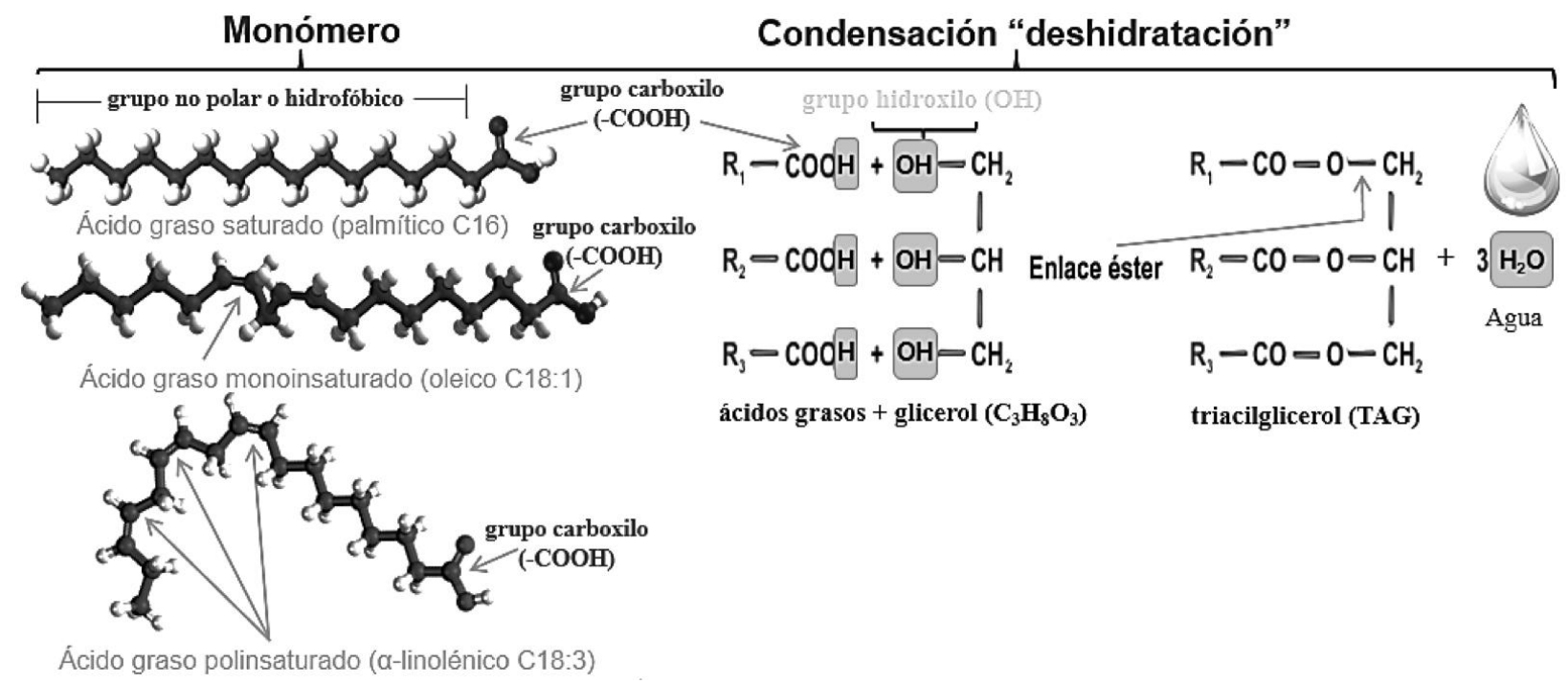

Figura 12. Formación de triacilglicerol con enlace éster

CATABOLISMO DEL TRIACILGLICEROL (LIPÓLISIS) Y CETOGÉNESIS Cuando las reservas de glucógeno en el citoplasma de miocitos y hepatocitos disminuyen, se activa la carnitina palmitoiltransferasa (Longo et al., 2016), estimulando 
el transporte de AGNE hacia el interior de la mitocondria hepática (Merritt et al., 2020; Wang et al., 2020). Donde la $\beta$-oxidación, conduce a una descarboxilación de los AGNE

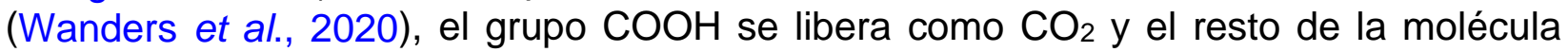
presenta deshidrogenación, estableciendo el grupo $\mathrm{COCH}_{3}$ (Botham \& Mayes, 2018b). La Coenzima $\mathrm{A}$, se transfiere al grupo $\mathrm{COCH}_{3}$ y forma acetil-Coenzima A (Guoyao, 2017f). Esta molécula se combina con oxaloacetato para su ingreso al ciclo de Krebs (Appleton et al., 2013c). Si su oxidación es completa, se liberará $\mathrm{CO}_{2}$ y pares de átomos de $\mathrm{H}$ (Friedman \& Nunnari, 2014), que donarán sus electrones para efectuar reacciones de óxido reducción (Madigan et al., 2019c), la formación de $\mathrm{H}_{2} \mathrm{O}$ y almacenamiento de energía en forma de ATP (Jump, 2011).

Sin embargo, si el oxaloacetato no es suficiente, la acetil-Coenzima A se acumula dentro de la mitocondria (Longo et al., 2016). Posteriormente dos moléculas de acetil-Coenzima A reaccionan para formar acetoacetil-CoA, en una reacción catalizada por tiolasa (Merritt et al., 2018). El acetoacetil-CoA se condensa con otra molécula de acetil-Coenzima $A$, para formar $\beta$-hidroxi- $\beta$-metilglutaril-CoA (Mas, 2018a). A partir de esta molécula se metaboliza acetoacetato (AcAc), cuerpo cetónico que sale de la mitocondria y en el citoplasma del hepatocito puede reducirse a $\beta$-hidroxibutirato ( $\boldsymbol{\beta}$-HBA) (Selvaraj et al., 2020) o descarboxilarse lenta y espontáneamente hasta acetona (Ac) (Deemer et al., 2020).

\section{PROPIEDADES FISICOQUÍMICAS DE LAS PROTEÍNAS}

De las tres biomoléculas discutidas, las proteínas son las únicas que contienen átomos de nitrógeno (N) (Ferrier, 2017c). Están constituidas por la combinación de 20 aminoácidos (aa) (Ahern, 2019a), unidos mediante un enlace peptídico (Guoyao, 2017b). Este enlace de tipo covalente, une el grupo amino $\left(\mathbf{N H}_{2}\right)$ de un aa y el grupo $\mathrm{COOH}$ de otro, con la formación de una molécula de $\mathrm{H}_{2} \mathrm{O}$ (Madigan et al., 2019b). Las proteínas participan activamente en la homeostasis celular (Cooper, 2019b), p. ej., transportando O (Guoyao, 2017b), estructurando inmunoglobulinas (Kenneth \& Casey, 2017) y constituyendo enzimas (Ahern, 2019c).

Su ingreso en el organismo, es a partir del alimento y su hidrólisis (ruptura de enlaces peptídicos) por peptidasas o proteasas y aminotransferasas, producidas por las células acinares del páncreas (Ahern, 2019c). Posterior a esta hidrólisis se liberan aa (Rodwell, 2018a), para ser absorbidos por medio del epitelio intestinal (Guoyao, 2017e; Piña \& Flores, 2018), y transportados hacia los hepatocitos del hígado (Appleton et al., 2013b), para su posterior exportación hacia los tejidos periféricos

(Fernández \& Peimbert, 2018).

Dentro del citoplasma celular, los aa pueden perder su grupo $\mathrm{NH}_{2}$ y como esqueletos carbonados funcionar como: i) substrato para sintetizar $\mathrm{C}_{3} \mathrm{H}_{3} \mathrm{O}_{3}$ y posteriormente acetilCoenzima A (Appleton et al., 2013d), ii) estructurar purinas y neurotransmisores (Rodwell, 2018b) y iii) participar en la proteogénesis (Rodwell, 2018a; Madigan et al., 2019b) o en la ureogénesis (Nelson \& Cox, 2017a) principalmente. 


\section{ANABOLISMO DE LAS PROTEÍNAS (PROTEOGÉNESIS)}

La proteogénesis (Figura 13), comienza en el núcleo celular (Noller, 2017), con la transcripción del ribonucleico de transferencia (ARNt) (Nelson \& Cox, 2017d; Madigan et al., 2019d). Posteriormente, la enzima ARN-polimerasa realiza la transcripción del ribonucleico mensajero (ARNm) a partir de una secuencia de desoxirribonucleico (ADN) (Liu et al., 2013), que sirve como patrón o molde de la información genética (Litwack, 2018b). El ARNm se transporta hasta el retículo endoplasmático rugoso y a sus ribosomas (Weil, 2018b). Durante la iniciación, se forma un puente entre la subunidad ribosómica menor y la mayor (Weil, 2018a).

Por su parte, el ARNt (Figura 14), tienen que unirse con diferentes aminoacil-ARNtsintetasas (Rodnina \& Wintermeyer, 2016), para exponer el grupo $\mathrm{NH}_{2}$ de sus bases nitrogenadas (citosina, guanina, adenina y uracilo) y fijar el grupo $\mathrm{COOH}$ de los diferentes aa (Smith, 2020a).

Los aa transportados en el ARNt ingresan en el complejo ribosomal que presenta dos sitios de unión: i) el sitio P o peptidil y ii) el sitio A o aminoacil (Berk et al., 2006). La traducción se lleva a cabo en los ribosomas, mediante la lectura de tripletes (de tres en tres nucleótidos) llamados: codón para el ARNm y anticodón para el ARNt (Ingolia, 2014). La primera etapa de traducción, comienza cuando el extremo 5' del ARNm se inserta en la subunidad ribosómica menor (Nelson \& Cox, 2017d), exponiendo el codón iniciador adenina-uracilo-guanina o AUG para su unión con el primer anticodón uracilo-adeninacitosina o UAC, en el sitio peptidil (Angov, 2011), originando metionina como primer aa (Madigan et al., 2019d).

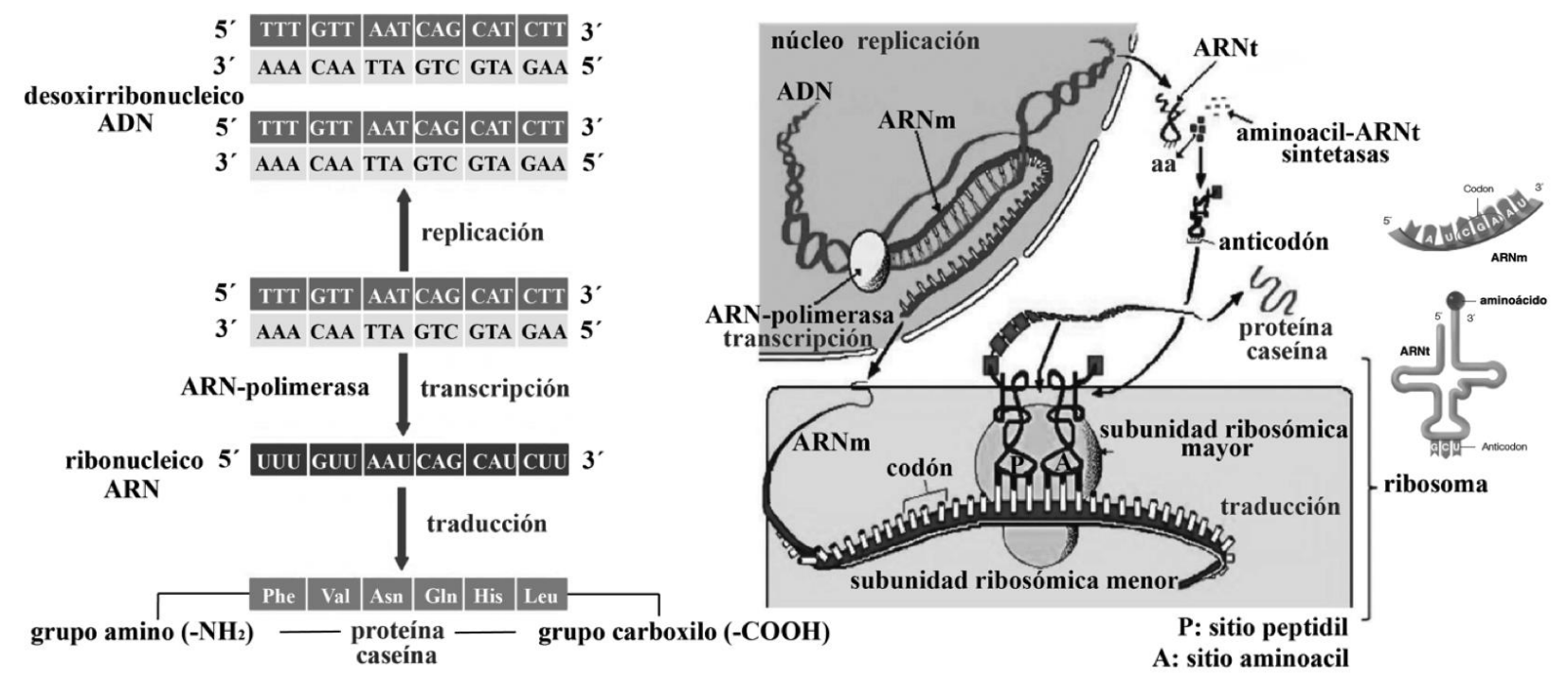

Figura 13. Proteogénesis, transcripción y traducción proteica

Fuente: (García et al., 2020). 


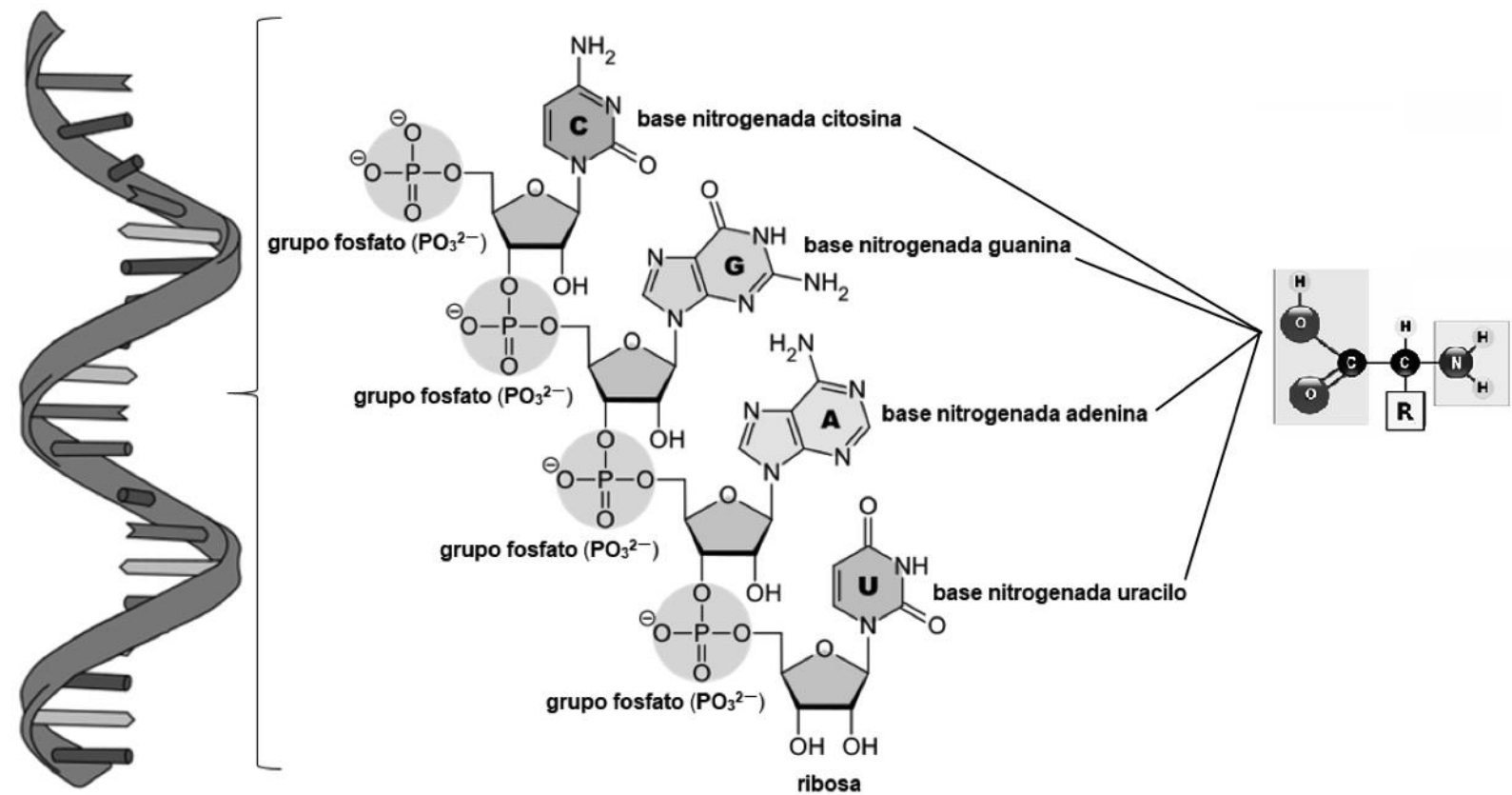

Figura 14. Ribonucleico de transferencia y su relación con aminoácidos en el citoplasma

Posteriormente, cuando el sitio peptidil y el sitio aminoacil están ocupados simultáneamente, la enzima peptidil transferasa establece un enlace peptídico entre los aa, insertando el primero en el segundo (Weil, 2018a). A continuación, en la elongación codón y anticodón se van asociando de manera precisa según la complementariedad de sus bases (Dutta \& Nandi, 2012), y esta secuencia de pasos es repetida según el número de aa que contenga el polipéptido (Madigan et al., 2019b). Como terminación de este proceso, se traducen diferentes proteínas y enzimas principalmente hidrolasas (Swiderek et al., 2015).

\section{CATABOLISMO DE LAS PROTEÍNAS (PROTEÓLISIS) Y UREOGÉNESIS}

Posterior a la digestión gástrica y enzimática de las proteínas, la ruptura de sus enlaces peptídicos, y la liberación y absorción de aa (Piña \& Flores, 2018), se obtiene también ion amonio $\left(\mathrm{NH}_{4}{ }^{+}\right.$) (Rodwell, 2018a). Esta molécula viaja al hígado, donde su primer contacto es con los hepatocitos periportales (Guoyao, 2017e), que poseen en su estructura enzimas ureagénicas encargadas de la síntesis de urea (Figura 15). En la mitocondria de los hepatocitos periportales, se condensan $\mathrm{HCO}_{3}{ }^{-}, \mathrm{NH}_{4}{ }^{+}$y ATP (Appleton et al., 2013b) para formar carbamil fosfato (Friedman \& Nunnari, 2014). La ornitina ingresa a la mitocondria y el carbamil fosfato cede su grupo carbamilo para formar citrulina (Weiner et al., 2015). 


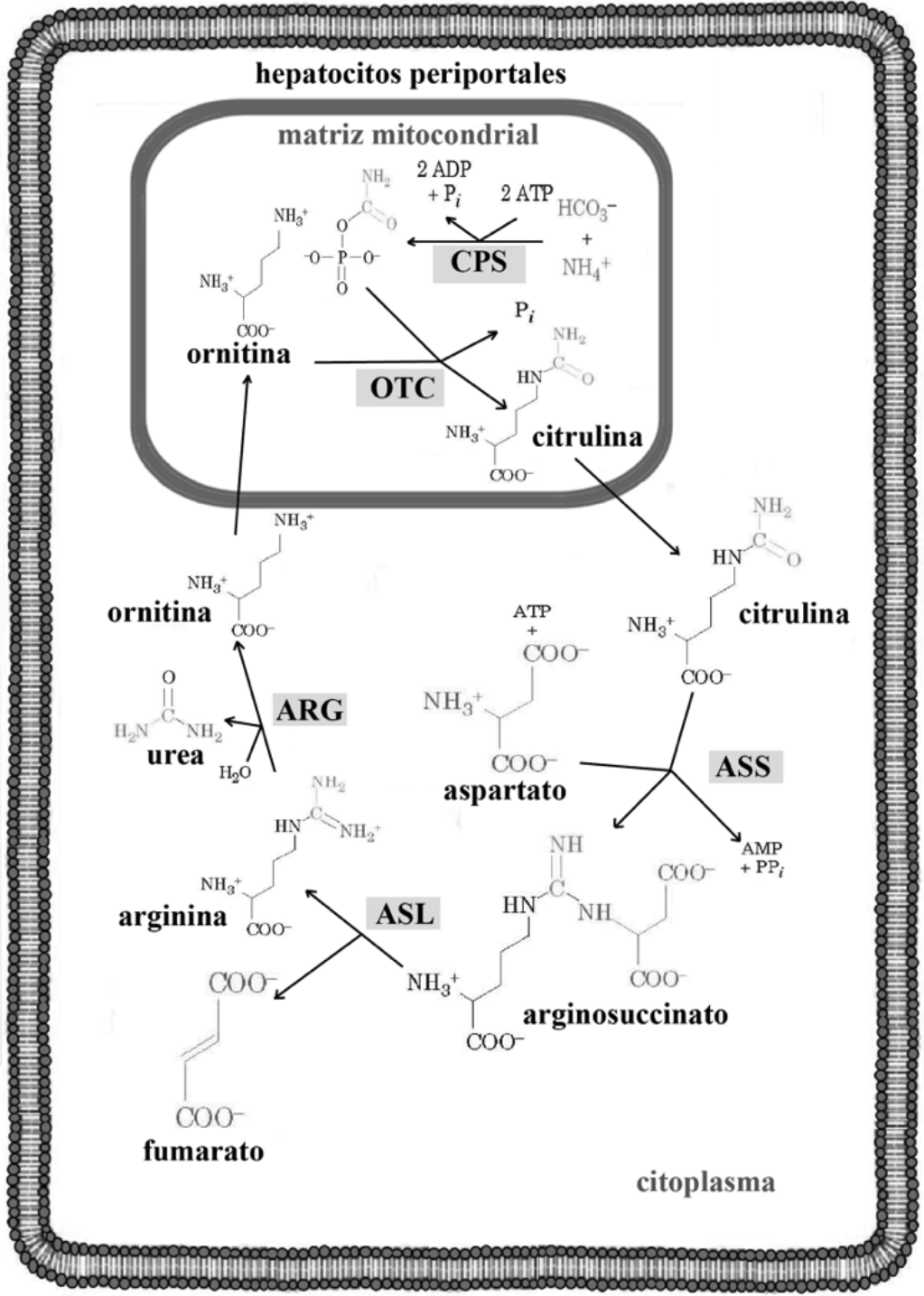

Figura 15. Ureogénesis

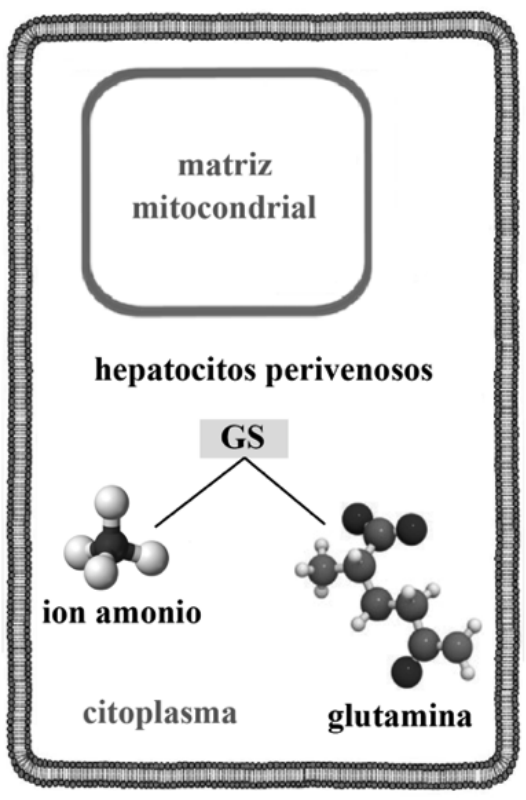

CPS carbamoil fosfato sintetasa

OTC ornitina transcarbamilasa

GS glutamina sintetasa

ASS argininosuccinato sintasa

ASL argininosuccinato liasa

ARG arginasa

Fuente: (García et al., 2020).

La citrulina sale de la mitocondria al citoplasma, donde se une al aspartato, formando arginosuccinato (Menzies et al., 2016). El arginosuccinato es dividido en dos: i) arginina (Arg) y ii) fumarato. La Arg es hidrolizada por la arginasa liberando urea y ornitina (Nelson \& Cox, 2017a). Esta última entra en la mitocondria para iniciar otra vuelta en el ciclo (Rodwell, 2018a). La urea por su parte, puede viajar al riñón (Guoyao, 2017b) y ser excretada en orina (Marini \& van Amburgh, 2003). El ion $\mathrm{NH}_{4}{ }^{+}$que no es metabolizado en urea, tiene contacto con los hepatocitos perivenosos, que poseen en su estructura glutamina sintetasa (Piña \& Flores, 2018), que convierte ion $\mathrm{NH}_{4}{ }^{+}$en glutamina (GIn). Este aa polar o hidrofílico, presenta afinidad por el $\mathrm{H}_{2} \mathrm{O}$ (Appleton et al., 2013b). Por lo tanto, favorece el transporte y excreción del ion $\mathrm{NH}_{4}{ }^{+}$en la orina (Rodwell, 2018a). 


\section{ANABOLISMO DE ADENOSINA TRIFOSFATO (CICLO DE KREBS)}

El ciclo de Krebs fue descubierto por Hans Adolf Krebs (Appleton et al., 2013c). Forma parte del intercambio gaseoso mitocondrial (Madigan et al., 2019c) y permite liberar la energía almacenada del acetil-Coenzima A en forma del nucleótido ATP (Botham \& Mayes, 2018d). El acetil-Coenzima A sede su grupo $\mathrm{COCH}_{3}$ para unirse con oxaloacetato y formar citrato mediante una reacción de condensación (Menzies et al., 2016; Verschueren et al., 2019). Durante una vuelta completa del ciclo y a través de hidrólisis, descarboxilación oxidativa e hidratación (Figura 16), el citrato se convierte de nuevo en oxaloacetato (Appleton et al., 2013d).

Los átomos de $\mathrm{C}$ que se liberan en el proceso forman $\mathrm{CO}_{2}$ (Madigan et al., 2019c). El ciclo de Krebs consume por cada vuelta un acetil-Coenzima $A$ y tres $\mathrm{NAD}^{+}$(Nelson \& Cox, 2017e). Produce por cada vuelta dos $\mathrm{CO}_{2}$ y tres $\mathrm{NADPH}+\mathrm{H}^{+}$(Friedman \& Nunnari, 2014). Por cada acetil-Coenzima $A$ que ingresa en el ciclo de Krebs se producen 12 ATP (Appleton et al., 2013c), cada uno formado por una base nitrogenada púrica o purina (adenina), unida a una ribosa (aldopentosa) y a tres $\mathrm{PO}_{4}{ }^{2-}$ (Botham \& Mayes, 2018a) (Figura 17).

Por cada $\mathrm{GLU}\left(\mathrm{C}_{6} \mathrm{H}_{12} \mathrm{O}_{6}\right)$ que ingresa en el ciclo se producen dos $\mathrm{C}_{3} \mathrm{H}_{3} \mathrm{O}_{3}$, que a su vez producen dos acetil-Coenzima A (Nelson \& Cox, 2017e). Por lo tanto, por cada GLU $\left(\mathrm{C}_{6} \mathrm{H}_{12} \mathrm{O}_{6}\right)$ que ingresa en el ciclo de Krebs se producen cuatro $\mathrm{CO}_{2}$, seis $\mathrm{NADPH}+\mathrm{H}^{+}$y 24 moléculas de ATP (Friedman \& Nunnari, 2014).

La información presentada en párrafos anteriores, muestra cómo las biomoléculas que constituyen los organismos vivos, interactúan para mantener y perpetuar la vida, gobernada por las mismas leyes físicas y químicas que gobiernan el universo inerte. La frontera del conocimiento, se organizó en torno a principios o cuestiones centrales de la bioquímica y cómo las células utilizan un conjunto relativamente pequeño de metabolitos basados en carbono para crear moléculas poliméricas, estructuras supramoleculares y depósitos de información. La estructura química de estos componentes define su función celular, cuyo resultado final es la transformación y la autoperpetuación de esa compilación de biomoléculas, en resumen, la vida.

\section{CONCLUSIONES}

Las células eucariontes están compuestas de agua, iones inorgánicos y moléculas orgánicas. Contienen cadenas carbonadas con grupos funcionales hidroxilo, amino y carboxilo, responsables de la formación de tejido celular. Estas estructuras obedecen las leyes de la química y la física que determinan el metabolismo de los sistemas vivos. Los animales al poseer una elevada complejidad química y una robusta organización microscópica, constituyen en su anabolismo y catabolismo molecular, sistemas de extracción, transformación y aprovechamiento de monosacáridos, aminoácidos y ácidos grasos. Para la formación de acetil-Coenzima A y la liberación de su energía en el ciclo de Krebs. Así, la bioquímica del metabolismo celular, puede entenderse en términos de las estructuras y funciones de tres clases principales de moléculas orgánicas polisacáridos, lípidos y proteínas. 


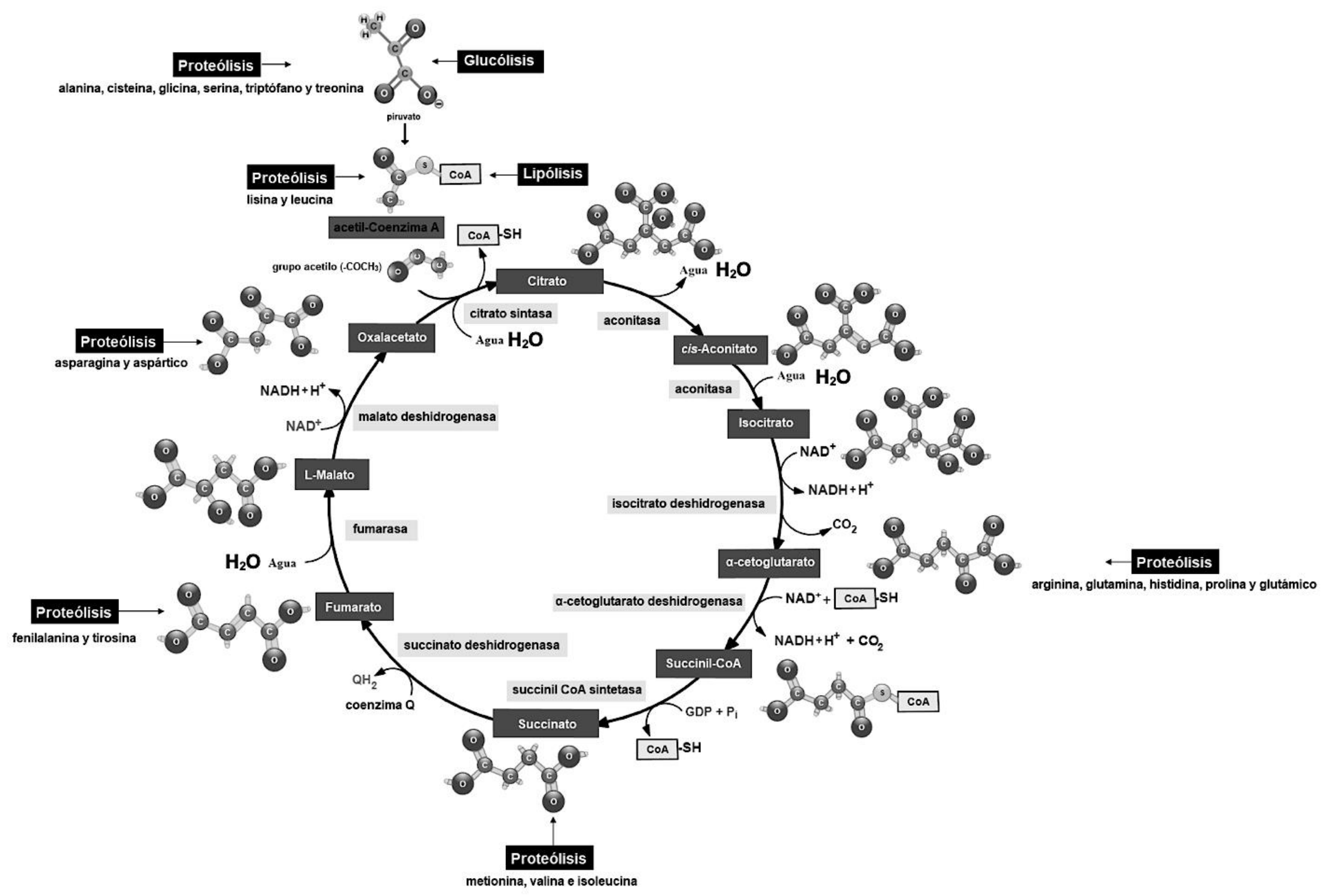

Figura 16. Ciclo de Krebs 


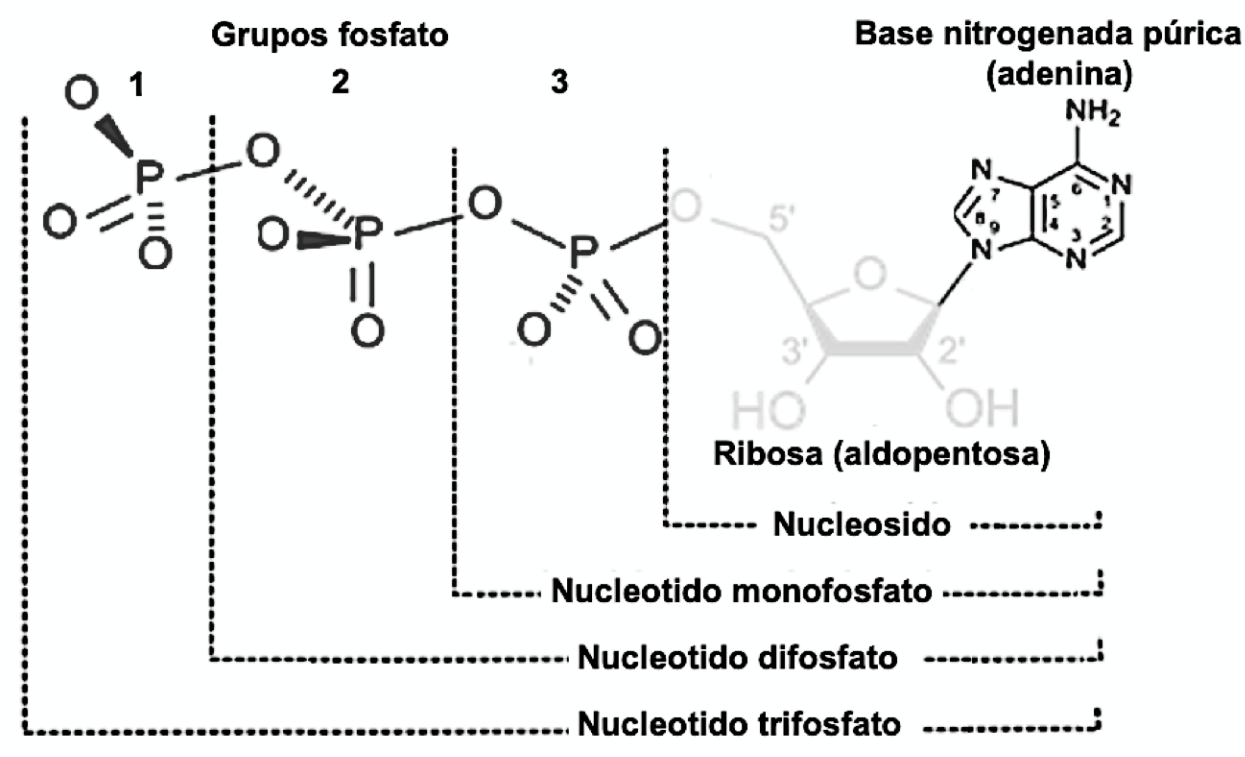

Figura 17. Nucleótido adenosina trifosfato (ATP)

\section{AGRADECIMIENTOS}

Este trabajo fue apoyado por el Consejo Nacional de Ciencia y Tecnología (CONACyTMéxico) y el proyecto: Perfiles metabólicos y sus implicaciones en medicina veterinaria (Universidad de Colima).

\section{LITERATURA CITADA}

AHERN K. 2019a. Amino acids: 20 building blocks of life. In: Ahern K, Biochemistry and Molecular Biology: How Life Works. Virginia, United States: The Teaching Company. Pp. 29-40. ISBN: 978-1-25-983793-7.

AHERN K. 2019b. Breaking down sugars and fatty acids. In: Ahern K, Biochemistry and Molecular Biology: How Life Works. Virginia, United States: The Teaching Company. Pp.120-126. ISBN: 978-1-25-983793-7.

AHERN K. 2019c. Enzyme regulation in cells. In: Ahern K, Biochemistry and Molecular Biology: How Life Works. Virginia, United States: The Teaching Company. Pp. 84-92. ISBN: 978-1-25-983793-7.

AHERN K. 2019d. How animals make carbs and fats. In: Ahern K, Biochemistry and Molecular Biology: How Life Works. Virginia, United States: The Teaching Company. Pp.158. ISBN: 978-1-25-983793-7.

AMEER F, Munir R, Zaidi N. 2018. Lipid metabolism. Reference Module in Biomedical Sciences. 1(1):1-4. ISSN: 9780128012383. http://dx.doi.org/10.1016/B978-0-12-8012383.64998-X 
ANGOV E. 2011. Codon usage: nature's roadmap to expression and folding of proteins. Biotechnology Journal. 6(6):650-659. ISSN: 1860-7314.

https://onlinelibrary.wiley.com/doi/10.1002/biot.201000332

APPLETON A, Vanbergen O, Dominiczak MH. 2013a. Metabolismo de los hidratos de carbono. En: Horton-Szar D, Lo Esencial en Metabolismo y Nutrición. Barcelona, España: Elsevier Health Sciences. Pp. 23-40. ISBN: 978-84-9022-416-8.

APPLETON A, Vanbergen O, Dominiczak MH. 2013b. Metabolismo de las proteínas. En: Horton-Szar D, Lo Esencial en Metabolismo y Nutrición. Barcelona, España: Elsevier Health Sciences. Pp. 71-82. ISBN: 978-84-9022-416-8.

APPLETON A, Vanbergen O, Dominiczak MH. 2013c. Metabolismo energético I: ciclo ATC. En: Horton-Szar D, Lo Esencial en Metabolismo y Nutrición. Barcelona, España: Elsevier Health Sciences. Pp. 13-17. ISBN: 978-84-9022-416-8.

APPLETON A, Vanbergen O, Dominiczak MH. 2013d. Metabolismo energético II: generación de ATP. En: Horton-Szar D, Lo Esencial en Metabolismo y Nutrición. Barcelona, España: Elsevier Health Sciences. Pp. 17-23. ISBN: 978-84-9022-416-8.

APPLETON A, Vanbergen O, Dominiczak MH. 2013e. Transporte y metabolismo de los lípidos. En: Horton-Szar D, Lo Esencial en Metabolismo y Nutrición. Barcelona, España: Elsevier Health Sciences. Pp. 45-70. ISBN: 978-84-9022-416-8.

BENDER AD, Mayes AP. 2018a. Glycolysis \& the oxidation of pyruvate. In: Rodwell WV, Bender AD, Botham MK, Kennelly JP, Weil AP, Harper's Illustrated Biochemistry. New York, United States: McGraw-Hill Education / Medical. Pp.400-404. ISBN: 978-1-25983794-4.

BENDER AD, Mayes AP. 2018b. Overview of metabolism \& the provision of metabolic fuels. In: Rodwell WV, Bender AD, Botham MK, Kennelly JP, Weil AP, Harper's Illustrated Biochemistry. New York, United States: McGraw-Hill Education / Medical. Pp. 336-342. ISBN: 978-1-25-983794-4.

BENDER AD, Mayes AP. 2018c. Physiologically important carbohydrates. n: Rodwell WV, Bender AD, Botham MK, Kennelly JP, Weil AP, Harper's Illustrated Biochemistry. United States: McGraw-Hill Education / Medical. Pp. 363-381. ISBN: 978-1-25-983794-4.

BERK V, Zhang W, Pai RD, Cate JH. 2006. Structural basis for mRNA and tRNA positioning on the ribosome. Proceedings of the National Academy of Sciences of the United States of America. 103(43):15830-15834. ISSN: 0027-8424. https://doi.org/10.1073/pnas.0607541103

BOTHAM MK, Mayes AP. 2018a. Bioenergetics: the role of ATP. In: Rodwell WV, Bender AD, Botham MK, Kennelly JP, Weil AP, Harper's Illustrated Biochemistry. United States: McGraw-Hill Education / Medical. Pp. 277-291. ISBN: 978-1-25-983793-7.

BOTHAM MK, Mayes AP. 2018b. Fatty acid oxidation: ketogenesis. In: Rodwell WV, Bender AD, Botham MK, Kennelly JP, Weil AP, Harper's Illustrated Biochemistry. United States: McGraw-Hill Education / Medical. Pp. 512-534. ISBN: 978-1-25-983793-7. 
BOTHAM MK, Mayes AP. 2018c. Lipids of physiological significance. In: Rodwell WV, Bender AD, Botham MK, Kennelly JP, Weil AP, Harper's Illustrated Biochemistry. United States: McGraw-Hill Education / Medical. Pp. 483-511. ISBN: 978-1-25-983793-7.

BOTHAM MK, Mayes AP. 2018d. The respiratory chain and oxidative phosphorylation. In: Rodwell WV, Bender AD, Botham MK, Kennelly JP , Weil AP, Harper's Illustrated Biochemistry. United States: McGraw-Hill Education / Medical. Pp. 308-335. ISBN: 9781-25-983793-7.

BOTICARIO BC, Cascales AM. 2012. Metabolismo de los carbohidratos. En: Boticario BC, Cascales AM, Digestión y Metabolismo Energético de los Nutrientes Plasencia, España: UNED. Pp. 86. ISBN: 978-84-615-8137-5.

CÁRABEZ TA, Sánchez AJ, Riveros RH. 2018a. Metabolismo de los carbohidratos. En: Hernández MMT, Bioquímica de Laguna y Piña. Ciudad de México, México: El Manual Moderno. Pp. 591-607. ISBN: 978-607-448-708-4.

CÁRABEZ TA, Sánchez AJ, Riveros RH. 2018b. Vía colateral de oxidación de la glucosa: ciclo de las pentosas. En: Hernández MMT, Bioquímica de Laguna y Piña. Ciudad de México, México: El Manual Moderno. Pp. 636-638. ISBN: 978-607-448-708-4.

COOPER GM. 2019a. The biosynthesis of cell constituents. Carbohydrates, lipids, proteins, adn nucleic acids. In: Cooper GM, The Cell: A Molecular Approach. Oxford, New York: Oxford University Press. Pp. 102-111. ISBN: 978-1-60535-707-2.

COOPER GM. 2019b. The molecules of cells. Chemical bonds, carbohydrates, lipids, nucleic acids y proteins. In: Cooper GM, The Cell: A Molecular Approach. Oxford, New York: Oxford University Press. Pp. 45-60. ISBN: 978-1-60535-707-2.

COOPER GM. 2019c. The origin and evolution of cells. In: Cooper GM, The Cell: $A$ Molecular Approach. Oxford, New York: Oxford University Press. Pp. 4-18. ISBN: 978-160535-707-2.

CHAVARRÍA KA, Cárabez TA. 2018. Química de los carbohidratos. En: Hernández MMT, Bioquímica de Laguna y Piña. Ciudad de México, México: El Manual Moderno. Pp. 416431. ISBN: 978-607-448-708-4.

DASHTY M. 2013. A quick look at biocheistry: carbohydrate metabolism. Clinical Biochemistry. 46(1):1339-1352. ISSN: 1873-2933.

https://doi.org/10.1016/j.clinbiochem.2013.04.027

DEEMER SE, Plaisance EP, Martins C. 2020. Impact of ketosis on appetite regulation-a review. Nutrition Research. 77(1):1-11. ISSN: 1879-0739.

https://doi.org/10.1016/j.nutres.2020.02.010

DELBIANCO M, Bharate P, Varela-Aramburu S, Seeberger PH. 2016. Carbohydrates in supramolecular chemistry. Chemical Reviews. 116(4):1693-16752. ISSN: 1520-6890. https://doi.org/10.1021/acs.chemrev.5b00516 
DOWHAN W, Bogdanov M. 2016. Functional roles of lipids in membranes. In: Ridway ND, McLeod SR, Bichemistry of lipids, lipoproteins and membranes. Nova Scotia, Canada: Elsevier. Pp.1-40. ISBN: 0444634495.

DUTTA BS, Nandi N. 2012. Chirality and protein biosynthesis. Topics in Current Chemistry. 372(1):1-51. ISBN: 2364-8961. http://doi.org/10.1007/128_2012_369

ENGELKING LR. 2015. Gluconeogenesis. In: Engelking LR, Textbook of Veterinary Physiological Chemistry. Massachusetts, United States: Academic Press. Pp. 225-230. ISBN: 978-0-12-391909-0.

FAILS DA, Magee C. 2018a. Nutrition and metabolism. In: Fails DA, Magee C, Anatomy and physiology of farm animals. Hoboken, United States: John Wiley \& Sons. Pp. 413419. ISBN: 978-111-923-971-0.

FAILS DA, Magee C. 2018b. Transport across cell membranes. In: Fails DA, Magee C, Anatomy and physiology of farm animals. Hoboken, United States: John Wiley \& Sons. Pp. 36-43. ISBN: 978-111-923-971-0.

FERNÁNDEZ VDA, Peimbert TM. 2018. Aminoácidos y proteínas. En: Hernández MMT, Bioquímica de Laguna y Piña. Ciudad de México, México: El Manual Moderno. Pp. 217260. ISBN: 978-607-448-708-4.

FERRIER RD. 2017a. A introduction to metabolism and glucolysis. In: Shannon M, Biochemistry. Philadelphia, United States: Wolters Kluwer. Pp. 298-326. ISBN: 978-149634-449-6.

FERRIER RD. 2017b. Glycolysis and gluconeogenesis. In: Shannon M, Biochemistry. Philadelphia, United States: Wolters Kluwer. Pp. 449-462. ISBN: 1978-149-634-449-6.

FERRIER RD. 2017c. Protein structure and function. Amino acids. In: Shannon M, Biochemistry. Philadelphia, United States: Wolters Kluwer. Pp. 13-42. ISBN: 978-149634-449-6.

FOX SI, Sierra GP, Bari SO. 2017. Respiración y metabolismo celulares. En: Fox SI, Fisiología Humana New York, United States: McGraw-Hill Education / Medical. Pp. 833. ISBN: 978-607-151-413-4.

FRIEDMAN JR, Nunnari J. 2014. Mitochondrial form and function. Nature. 505(7483):335343. ISSN: 1476-4687. https://doi.org/10.1038/nature12985

GADUPUDI GS, Klingelhutz AJ, Robertson LW. 2016. Diminished Phosphorylation of CREB is a key event in the dysregulation of gluconeogenesis and glycogenolysis in PCB126 hepatotoxicity. Chemical Research in Toxicology. 29(1):1504-1509. ISSN: 0893228X. http://doi.org/10.1021/acs.chemrestox.6b00172

GARCÍA CAC, Prado ROF, H. PD. 2020. Fisiología del período de transición, posparto y retorno al estro en vacas lecheras: desafíos para la producción sustentable. En: Gutiérrez NNS, Gutiérrez VMC, Ramírez GMJ, Handbook T-Il Sustentabilidad, turismo y educación. México, Ciudad de México: ECORFAN-México, S.C. Pp. 63-86. ISBN: 978607-8695-29-4. 
GUNDU HRR. 2020. Cardiometabolic diseases: Biochemistry, Pathophysiology and medical innovations. Biochemistry and Modern Applications. 3(1):1-5. ISSN: 2638-7735. http://doi.org/10.33805/2638-7735.126

GUOYAO W. 2017a. Chemistry of lipids. In: Guoyao W, Principles of Animal Nutrition. New York, United States: CRC Press. Pp. 109-142. ISBN: 978-1-4987-2160-8.

GUOYAO W. 2017b. Chemistry of protein and amino acids. In: Guoyao W, Principles of Animal Nutrition. New York, United States: CRC Press. Pp. 149-188. ISBN: 978-1-49872160-8.

GUOYAO W. 2017c. Introduction to metabolism. In: Guoyao W, Principles of Animal Nutrition. New York, United States: CRC Press. Pp. 67-69. ISBN: 978-1-4987-2160-8.

GUOYAO W. 2017d. Nutrition and metabolism of lipids. In: Guoyao W, Principles of Animal Nutrition. New York, United States: CRC Press. Pp. 271-338. ISBN: 978-1-49872160-8.

GUOYAO W. 2017e. Nutrition and metabolism of protein and amino acids. In: Guoyao W, Principles of Animal Nutrition. New York, United States: CRC Press. Pp. 349-411. ISBN: 978-1-4987-2160-8.

GUOYAO W. 2017f. Pathway of glycolysis. In: Guoyao W, Principles of Animal Nutrition. New York, United States: CRC Press. Pp. 219. ISBN: 978-1-4987-2160-8.

INGOLIA NT. 2014. Ribosome profiling: new views of translation, from single codons to genome scale. Nature Reviews Genetics. 15(3):205-213. ISSN: 1471-0064. https://doi.org/10.1038/nrg3645

JAMESON LJ. 2017. Electrolitos y equilibrio ácido-base. En: Kasper LD, Fauci SA, Hauser LS, Longo LD, Jameson LJ , Loscalzo J, Harrison. Manual de medicina. Ciudad de México, México: McGraw-Hill. Pp.1-23. ISBN: 978-607-15-1409-7.

JUMP DB. 2011. Fatty acid regulation of hepatic lipid metabolism. Current Opinion in Clinical Nutrition \& Metabolic Care. 14(2):115-120. ISSN: 1473-6519. http://doi.org/10.1097/MCO.0b013e328342991c

KENNETH M, Casey W. 2017. The humoral immune response. In: Toledo M, Janeway's Immunobiology. New York, United States: Garland Science. Pp. 399-445. ISBN: 978-081534-505-3.

KUMAR S, Chakravarty S. 2018. Amylases. In: Simões NC, Kumar V, Enzymes in Human and Animal Nutrition: Principles and Perspectives. New York, United States: Academic Press. Pp. 163-175. ISBN: 978-012-809-426-6.

LEE MH, Malloy CR, Corbin IR, Li J, Jin ES. 2019. Assessing the pentose phosphate pathway using [2, 3-13C2] glucose. NMR in Biomedicine. 1(1):1-10. ISSN: 1099-1492. https://doi.org/10.1002/nbm.4096

LITWACK DG. 2018a. Glycogen and glycogenolysis. In: Litwack DG, Human Biochemistry. California, United States: Academic press. Pp. 183-198. ISBN: 978-0-12383864-3. 
LITWACK DG. 2018b. Proteins biosynthesis. In: Litwack DG, Human Biochemistry. California, United States: Academic press. Pp. 319-336. ISBN: 978-0-12-383864-3.

LIU X, Bushnell DA, Kornberg RD. 2013. RNA polymerase II transcription: structure and mechanism. Biochimica et Biophysica Acta. 1829(1):2-8. ISSN: 1874-9399. https://doi.org/10.1016/j.bbagrm.2012.09.003

LONGO N, Frigeni M, Pasquali M. 2016. Carnitine transport and fatty acid oxidation. Biochimica et Biophysica Acta. 1863(10):2422-2435. ISSN: 1874-9399. https://doi.org/10.1016/j.bbamcr.2016.01.023

MADIGAN TM, Bender SK, Buckley HD, Sattley WM, Stahl AD. 2019a. Biosyntheses. Sugars and polysaccharides. Amino acids and nucleotides. Fatty acids and lipids. En: Madigan TM, Brock Biology of Microorganisms. New York, United States: Pearson. Pp. 130-137. ISBN: 978-1-292-23510-3.

MADIGAN TM, Bender SK, Buckley HD, Sattley WM, Stahl AD. 2019b. Protein synthesis: translation. In: Madigan TM, Brock Biology of Microorganisms. New York, United States: Pearson. Pp. 156-170. ISBN: 978-1-292-23510-3.

MADIGAN TM, Bender SK, Buckley HD, Sattley WM, Stahl AD. 2019c. Respiratory processes defined by electron donor. Hydrogen $\left(\mathrm{H}_{2}\right)$ oxidation. In: Madigan TM, Brock Biology of Microorganisms. New York, United States: Pearson. Pp. 446-449. ISBN: 9781-292-23510-3.

MADIGAN TM, Bender SK, Buckley HD, Sattley WM, Stahl AD. 2019d. RNA synthesis: transcription In: Madigan TM, Brock Biology of Microorganisms. New York, United States: Pearson. Pp. 151-155. ISBN: 978-1-292-23510-3.

MARINI JC, van Amburgh ME. 2003. Nitrogen metabolism and recycling in Holstein heifers. Journal of Animal Science. 81(2):545-552. ISSN: 0021-8812. https://doi.org/10.2527/2003.812545x

MAS OJ. 2018a. Metabolismo de los lípidos. En: Hernández MMT, Bioquímica de Laguna y Piña. Ciudad de México, México: El Manual Moderno. Pp. 660-785. ISBN: 978-607-448708-4.

MAS OJ. 2018b. Química de los lípidos. En: Hernández MMT, Bioquímica de Laguna y Piña. Ciudad de México, México: El Manual Moderno. Pp. 456-483. ISBN: 978-607-448708-4.

MCKEE T, Mckee JR. 2014a. Carbohidratos. En: De León-Fraga J, Bioquímica. Las bases moleculares de la vida Ciudad de México, México: McGraw-Hil. Pp. 208-212. ISBN: 978-0-19-992046-4.

MCKEE T, Mckee JR. 2014b. Metabolismo aerobio II: transporte de electrones y fosforilación oxidativa. En: De León-Fraga J, Bioquímica. Las bases moleculares de la vida Ciudad de México, México: McGraw-Hil. Pp. 308. ISBN: 978-0-19-992046-4.

MCKEE T, Mckee JR. 2014c. Metabolismo de los carbohidratos. En: De León-Fraga J, Bioquímica. Las bases moleculares de la vida Ciudad de México, México: McGraw-Hil. Pp. 240-250. ISBN: 978-0-19-992046-4. 
MELO V, Cuamatzi OT. 2019. Glucólisis: ruta central del catabolismo de la glucosa. En: Melo V, Bioquímica de los procesos metabólicos. Barcelona, España: Reverté. Pp. 169177. ISBN: 978-84-291-9551-4.

MENZIES KJ, Zhang H, Katsyuba E, Auwerx J. 2016. Protein acetylation in metabolism metabolites and cofactors. Nature Reviews Endocrinology. 12(1):43-60. ISSN: 17595037. https://doi.org/10.1038/nrendo.2015.181

MERRITT JL, Norris M, Kanungo S. 2018. Fatty acid oxidation disorders. Annals of Translational Medicine. 6(24):473-475. ISSN: 2305-5839. http://doi.org/10.21037/atm.2018.10.57

MERRITT JL, MacLeod E, Jurecka A, Hainline B. 2020. Clinical manifestations and management of fatty acid oxidation disorders. Reviews in Endocrine and Metabolic Disorders. 21(4):479-493. ISSN:1573-2606. https://doi.org/10.1007/s11154-020-09568-3

MILANI P, França D, Balieiro AG, Faez R. 2017. Polymers and its applications in agriculture. Polímeros. 27(3):256-266. ISSN: 1988-4206. https://doi.org/10.1590/01041428.09316

NELSON LD, Cox MM, Hoskins AA. 2021a. Amino acids, peptides, and proteins. In: Nelson LD , Cox MM, Hoskins AA, Lehninger. Principles of Biochemistry. New York, United States: Macmillan Learning. Pp. 357-392. ISBN: 978-1-319-32234-2.

NELSON LD, Cox MM, Hoskins AA. 2021b. Glycolysis, gluconeogenesis and the pentose phosphate patway. In: Nelson LD , Cox MM, Hoskins AA, Lehninger. Principles of Biochemistry. New York, United States: Macmillan Learning. Pp. 1865-2000. ISBN: 9781-319-32234-2.

NELSON LD, Cox MM, Hoskins AA. 2021c. Storage lipids. In: Nelson LD , Cox MM, Hoskins AA, Lehninger. Principles of Biochemistry. New York, United States: Macmillan Learning. Pp. 1286-1292. ISBN: 978-1-319-32234-2.

NELSON LD, Cox MM, Hoskins AA. 2021d. RNA metabolism In: Nelson LD , Cox MM, Hoskins AA, Lehninger. Principles of Biochemistry. New York, United States: Macmillan Learning. Pp. 3341-3380. ISBN: 978-1-319-32234-2.

NELSON LD, Cox MM, Hoskins AA. 2021e. ATP synthesis. In: Nelson LD , Cox MM, Hoskins AA, Lehninger. Principles of Biochemistry. New York, United States: Macmillan Learning. 2407-2446 p. ISBN: 978-1-319-32234-2.

NOLLER HF. 2017. The parable of the caveman and the Ferrari: protein synthesis and the RNA world. Topics in Current Chemistry. 372(1):1-5. ISSN: 1471-2970. https://doi.org/10.1098/rstb.2016.0187

NUNES-NESI A, Araujo WL, Obata T, Fernie AR. 2013. Regulation of the mitochondrial tricarboxylic acid cycle. Current Opinion in Plant Biology. 16(3):335-343. ISSN: 18790356. https://doi.org/10.1016/j.pbi.2013.01.004

OOSTERVEER MH, Schoonjans K. 2014. Hepatic glucose sensing and integrative pathways in the liver. Cellular and Molecular Life Sciences. 71(8):1453-1467. ISSN: 14209071. https://doi.org/10.1007/s00018-013-1505-z 
PAVLINOV I, Gerlach EM, Aldrich LN. 2019. Next generation diversity-oriented synthesis: a paradigm shift from chemical diversity to biological diversity. Organic and Biomolecular Chemistry. 17(7):1608-1623. ISSN: 1477-0539. https://doi.org/10.1039/C8OB02327A

PIÑA GE, Flores HO. 2018. Metabolismo de los compuestos nitrogenados. En: Hernández MMT, Bioquímica de Laguna y Piña. Ciudad de México, México: El Manual Moderno. Pp. 714-763. ISBN: 978-607-448-708-4.

POL A, Gross SP, Parton RG. 2014. Review: biogenesis of the multifunctional lipid droplet: lipids, proteins and sites. Journal of Cell Biology. 204(5):635-646. ISSN: 15408140. https://doi.org/10.1083/jcb.201311051

PRATT LR, Chaudhari MI, Rempe SB. 2016. Statistical analyses of hydrophobic interactions. Journal of Physical Chemistry B. 120(27):6455-6460. ISSN: 1520-5207. https://doi.org/10.1021/acs.jpcb.6b04082

PREETHI KA, Sekar D. 2021. Dietary microRNAs: Current status and perspective in food science. Journal of Food Biochemistry. 45(7):e13827-e13832. ISSN: 1745-4514. https://doi.org/10.1111/jfbc.13827

QUINTERO FG. 2014. Gliceroneogénesis y el ciclo del triacilglicerol. En: De León-Fraga $\mathrm{J}$, Bioquímica. Las bases moleculares de la vida Ciudad de México, México: McGraw-Hil. Pp. 383-384. ISBN: 978-0-19-992046-4.

RODNINA MV, Wintermeyer W. 2016. Protein elongation, co-translational folding and targeting. Journal of Molecular Biology. 1(1):1-51. ISSN: 0022-2836. https://doi.org/10.1016/j.jmb.2016.03.022

RODWELL WV. 2018a. Catabolism of proteins and amino acid nitrogen. In: Rodwell WV, Bender AD, Botham MK, Kennelly JP, Weil AP, Harper's Illustrated Biochemistry. United States: McGraw-Hill Education / Medical. Pp. 661-686. ISBN: 978-1-25-983793-7.

RODWELL WV. 2018b. Metabolism of purine and pyrimidine nucleotides. In: Rodwell WV, Bender AD, Botham MK, Kennelly JP , Weil AP, Harper's Illustrated Biochemistry. United States: McGraw-Hill Education / Medical. Pp. 801-826. ISBN: 978-1-25-983793-7.

RUI L. 2014. Energy metabolism in the liver. Comprehensive Physiology. 4(1):177-197. ISSN: 20404603. https://doi.org/10.1002/cphy.c130024

SCHOELER M, Caesar R. 2019. Dietary lipids, gut microbiota and lipid metabolism. Reviews in Endocrine and Metabolic Disorders. 1(1):1-12. ISSN: 13899155. https://doi.org/10.1007/s11154-019-09512-0

SELVARAJ S, Kelly DP, Margulies KB. 2020. Implications of altered ketone metabolism and therapeutic ketosis in heart failure. Circulation. 141(22):1800-1812. ISSN: 1524-4539. https://doi.org/10.1161/CIRCULATIONAHA.119.045033

SMITH BM. 2020a. Amino acids. En: Smith BM, Biochemistry: An Organic Chemistry Approach. New York, United States: CRC Press. Pp. 253-259. ISBN: 9780815366454.

SMITH BM. 2020b. The importance of water in biochemical systems. In: Smith BM, Biochemistry: An Organic Chemistry Approach. New York, United States: CRC Press. Pp. 55-80. ISBN: 9780815366454. 
STINCONE A, Prigione A, Cramer T, Wamelink MM, Campbell K, Cheung E, OlinSandoval V, Gruning NM, Kruger A, Tauqeer AM, Keller MA, Breitenbach M, Brindle KM, Rabinowitz JD, Ralser M. 2015. The return of metabolism: biochemistry and physiology of the pentose phosphate pathway. Biological Reviews of the Cambridge Philosophical Society. 90(3):927-963. ISSN: 1469-185X. https://doi.org/10.1111/brv.12140

SWIDEREK K, Marti S, Tunon I, Moliner V, Bertran J. 2015. Peptide bond formation mechanism catalyzed by ribosome. Journal of the American Chemical Society. 137(37):12024-12034. ISSN: 1520-5126. https://doi.org/10.1021/jacs.5b05916

TORTORA JG, Derrickson B. 2018a. Metabolismo de lípidos. En: Rondinone S, Principios de Anatomía y Fisiología. Ciudad de México, México: Médica Panamericana. Pp. 968969. ISBN: 978-607-854-611-4.

TORTORA JG, Derrickson B. 2018b. Metabolismo y nutrición. En: Rondinone S, Principios de Anatomía y Fisiología. Ciudad de México, México: Médica Panamericana. Pp. 956. ISBN: 978-607-854-611-4.

TORTORA JG, Funke RB, Case LC. 2019a. Organic compounds. Structure and chemistry: carbohydrates, lipids, proteins, nucleic acids. In: Beauparlant S, Microbiology: An Introduction. New York, United States: Pearson. Pp. 33-47. ISBN:978-607-854-611-4.

TORTORA JG, Funke RB, Case LC. 2019b. The structure of atoms. How atoms form molecules: chemical bonds. In: Beauparlant S, Microbiology: An Introduction. New York, United States: Pearson. Pp. 25-30. ISBN: 978-607-854-611-4.

VERSCHUEREN KHG, Blanchet C, Felix J, Dansercoer A, De Vos D, Bloch Y, Van Beeumen J, Svergun D, Gutsche I, Savvides SN, Verstraete K. 2019. Structure of ATP citrate lyase and the origin of citrate synthase in the Krebs cycle. Nature. 568(7753):571575. ISSN: 1476-4687. https://doi.org/10.1038/s41586-019-1095-5

VOET D, Voet JG, Pratt CW. 2016. Glucose catabolism. In: Ray B, Life at the molecular leve/ New York, United States: Wiley. Pp. 478-495. ISBN: 978-1-118-91840-1.

WADHERA RK, Steen DL, Khan I, Giugliano RP, Foody JM. 2016. A review of low-density lipoprotein cholesterol, treatment strategies, and its impact on cardiovascular disease morbidity and mortality. Journal of Clinical Lipidology. 10(3):472-489. ISSN: 1933-2874. https://doi.org/10.1016/j.jacl.2015.11.010

WANDERS RJA, Visser G, Ferdinandusse S, Vaz FM, Houtkooper RH. 2020. Mitochondrial fatty acid oxidation disorders: laboratory diagnosis, pathogenesis, and the complicated route to treatment. Journal of Lipid and Atherosclerosis. 9(3):313-333. ISSN: 2287-2892. https://doi.org/10.12997/jla.2020.9.3.313

WANG A, Richhariya A, Gandra SR, Calimlim B, Kim L, Quek RG, Nordyke RJ, Toth PP. 2016. Systematic review of low-density lipoprotein cholesterol apheresis for the treatment of familial hypercholesterolemia. Journal of the American Heart Association. 5(7):1-12. ISSN: 2047-9980. https://doi.org/10.1161/JAHA.116.003294

WANG W, Zh N, Yan T, Ya-Ning S, Chen J, Chan-Juan Z, Xue-Jiao X, Duan-Fang L, Qin L. 2020. The crosstalk: exosomes and lipid metabolism. Cell Communication and Signaling. 18(3):1-13. ISSN: 1478-811X. https://doi.org/10.1186/s12964-020-00581-2 
WEIL AP. 2018a. Protein synthesis and the genetic code. In: Rodwell WV, Bender AD, Botham MK, Kennelly JP, Weil AP, Harper's Illustrated Biochemistry. United States: McGraw-Hill Education / Medical. Pp. 955-991. ISBN: 978-1-25-983793-7.

WEIL AP. 2018b. RNA synthesis, processing and modification. In: Rodwell WV, Bender AD, Botham MK, Kennelly JP , Weil AP, Harper's Illustrated Biochemistry. United States: McGraw-Hill Education / Medical. Pp. 911-954. ISBN: 978-1-25-983793-7.

WEINER ID, Mitch WE, Sands JM. 2015. Urea and ammonia metabolism and the control of renal nitrogen excretion. Clinical Journal of the American Society of Nephrology. 10(8):1444-1458. ISSN: 1555-905X. https://doi.org/10.2215/CJN.10311013

WU T, Jiang Q, Wu D, Hu Y, Chen S, Ding T, Ye X, Liu D, Chen J. 2019. What is new in lysozyme research and its application in food industry? A review. Food Chemistry. 274(1):698-709. ISSN: 1873-7072. https://doi.org/10.1016/j.foodchem.2018.09.017

YANG Y, Zhang X, Yu B. 2015. O-Glycosylation methods in the total synthesis of complex natural glycosides. Natural Product Reports. 32(9):1331-1355. ISSN: 1460-4752. https://doi.org/10.1039/c5np00033e 